\title{
TESTIMONIO KALLAWAYA. MEDICINA INDÍGENA EN LA CIUDAD \\ DE «LA PAZ» (BOLIVIA)
}

\author{
Gerardo Fernández Juárez
}

Universidad de Castilla-La Mancha

\section{RESUMEN}

El artículo presenta el caso de los médicos kallawayas en la ciudad de La Paz como reflejo de la situación multicultural que la ciudad boliviana vive en relación con la salud y otros ámbitos específicos de la cultura. El testimonio de Severino Vila, médico kallawaya, nos aproxima a los patrones kallawayas que inciden en los determinantes sobre salud y enfermedad que son pertinentes en las soluciones terapéuticas que proponen. Las categorías médicas kallawayas no coinciden con las propias de la medicina occidental, dando lugar a diferentes opciones de exclusividad y complementación en el itinerario de salud recorrido por los pacientes indígenas de la ciudad de La Paz.

\section{SUMMARY}

The present paper shows the case study of kallawaya doctors in La Paz city as reflecting the multicultural situation that Bolivian city is living with regard to health and other particular aspects of the culture. The Severino Vilas's testimony, who is a kallawaya doctor, approaches us to the kallawaya patterns which affet the determinants on health and illness relevant in therapeutic solutions. The kallawaya medical categories do not coincide with those of occidental medicine, so different exclusiveness and complementariness options are rising in the healthy way carried out by native patients from $\mathrm{La} \mathrm{Paz}$ city.

\section{INTRODUCCIÓN.}

La ciudad de La Paz, capital política de Bolivia, constituye un mosaico de formas culturales diferentes, extendidas sobre los escalones que constituyen su peculiar orografía, entre los 3.600 metros de altura en que se localizan las barriadas nobles de Calacoto, Achumani y Los Pinos, hasta los 4.000 metros que alcanza la Ceja de El Alto en pleno altiplano andino, principal nudo de comunicaciones situado en la ciudad anexa a La Paz conocida con la elocuente denominación de «El Alto».

En este intrincado espacio natural conviven diferentes grupos étnicos, lenguas y culturas, apreciándose un componente indígena que resulta predominante, el corres- 
pondiente a los aymara altiplánicos ${ }^{1}$. Las diferentes expresiones religiosas y festivas muestran la vigencia de las conceptualizaciones culturales indígenas y mestizas, así como sus reinterpretaciones urbanas, frente a la ortodoxia católica y las formas del poder político y social ejercido por la minoría blanca. En este contexto social y cultural el ejercicio de la medicina encuentra posibilidades igualmente diversas.

La atención médico sanitaria convencional, no cubre a todos los bolivianos de igual forma. Tan sólo algunos gremios de trabajadores entre los que destaca el magisterio, ciertos funcionarios administrativos y algunas empresas mineras así como particulares, ofrecen un seguro médico a sus asociados. La mayor parte de la población queda al margen de este tipo de convenios, muy especialmente las poblaciones indígenas que tan sólo reciben el beneficio de los sistemas de postas sanitarias, habitualmente regidas y administradas por parte de ONGs foráneas, que dependen de algún pequeño hospital que hace las veces de centro articulador del sistema ambulatorio de postas a cargo de auxiliares sanitarios nativos. Las posibilidades de «socialización» de dichas postas, depende en gran medida de la capacidad de relación y afinidad que los equipos sanitarios consigan con sus pacientes indígenas y con los propios médicos aborígenes detentadores del rol médico tradicional.

En las ciudades de La Paz y El Alto, la atención sanitaria ofrece múltiples posibilidades. Las clases pudientes no dudan en despreciar el seguro médico, abonando importantes cantidades en clínicas privadas, dotadas de mejores medios que algunas instituciones hospitalarias públicas, cuando precisan de atención médica. Las clases populares, tanto mestizas como indígenas, no dudan en conjugar las formas de terapia tradicionales con la consulta médica convencional. En ciertas ocasiones, cuando la etiología del mal lo aconseja, es el curandero indígena, yatiri, en aymara, jampiri en quechua, quien es consultado para la resolución del problema, con exclusividad. Si bien la complementación parece el recurso habitual en la ciudad de La Paz, sí se establece una marcada diferenciación cuando la medicina «es para el doctor» o cuando «es de la gente» implicando al curandero tradicional. Las enfermedades y dolencias «de la gente», no puede sanarlas el médico. Las dolencias del «susto», la pérdida del ajayu, el mal «aire», o el mal de los «gentiles» o chullpas, no son consultados al médico, pesto que «no entiende» de dichas afecciones, y acostumbra a increpar en ocasiones al propio paciente por su «credulidad», lo cual dificulta de forma severa las relaciones entre médico y enfermo.

Las poblaciones indígenas de América del Sur han desarrollado diferentes respuestas frente a las dolencias, aflicciones y enfermedades habituales de su entorno. Por un lado poseen determinados síndromes patológicos de marcado carácter cultural que surgen en el seno de un grupo étnico concreto quien desarrolla las pautas preventivas y terapéuticas más convenientes para la correcta resolución de dicho síndrome o

1 Albó, X. (1995) Bolivia plurilingüe. Vol II, p. 73, La Paz. 
conjunto de síntomas culturalmente establecidos ${ }^{2}$. Este tipo de dolencias surgen en el entramado de aspectos que constituyen la cultura y responden a una naturaleza y etiología que habitualmente compromete otros parámetros esenciales en las características culturales del grupo. Las tácticas y estrategias curativas que surgen en atención a este tipo de síntomas responden a la conceptualización que el grupo establece sobre la enfermedad y su naturaleza, encontrando sentido y eficacia en la propia trama cultural que el grupo sostiene y no fuera de ella. Este tipo de enfermedades son las habitualmente vedadas para los servicios de salud formales que pretenden tratar la enfermedad de una forma «convencional» en las poblaciones indígenas de América.

Otro tipo de dolencias son las definidas como ajenas al grupo que las padece y su resolución depende de la actuación de las postas y centros sanitarios de salud; los médicos adquieren un reconocimiento y competencia en el tratamiento de este tipo de afecciones.

El problema surge respecto a las dolencias que dentro del grupo se identifican con una etiología concreta de marcado carácter cultural, mientras los equipos médicos establecen una orientación diferente, impulsando una competencia de agentes diferenciados y cierta confusión respecto al tratamiento a seguir, lo cual genera con frecuencia serias dudas y desconfianza sobre las «garantías» de las medidas propuestas por los equipos de salud.

La implicación de la salud, la medicina y las formas de conceptualización de la enfermedad con respecto a las diferentes modalidades culturales que adquiere entre los grupos indígenas americanos, ha despertado temprano el interés de antropólogos y etnógrafos por las consideraciones aborígenes sobre la enfermedad y su tratamiento, constituyendo un apartado obligatorio en las monografías clásicas.

La antropología médica, excindida reciéntemente de la antropología social y cultural, pretende como objeto de estudio y análisis todos aquellos aspectos implicados en la conceptualización cultural de la enfermedad y su resolución terapéutica ${ }^{3}$. Constituye una perspectiva analítica particularmente oportuna en ciertos Estados de América Latina, de marcado talante pluricultural y multilingüe, donde las aplicaciones médicas adoptan multitud de formatos divergentes y las prácticas y categorías cognitivas diferenciadas entran en conflicto frecuente con las aspiraciones de la medicina

\footnotetext{
2 La bibliografía sobre medicinas indígenas, donde se definen dichos síndromes culturales, resulta importante y extensa. Sirvan como simples referencias las siguientes:

Aguirre, G. (1992) Obra Antropológica VIII. Medicina y magia, México; AguIRre, G. (1994) Obra Antropológica XIII. Antropología Médica, México; Holland, W (1963) Medicina Maya en los Altos de Chiapas, México; AMODIO, E \& JuncosA, J. (comp. ) (1991) Los espíritus aliados, Quito; BALLADELLI, P. (1988) Entre lo mágico y lo natural. La medicina indígena. Testimonios de Pesillo, Quito; MuÑOZBERNAND, C. (1986) Enfermedad, daño e ideología, Quito; FERNÁNDEZ, G. (1996) «Modelos aymaras de salud:Ajllata Grande (Provincia Omasuyos)». Reunión Anual de Etnología 1995. Tomo I, 76-103, La Paz.

3 Comelles, J.M. y MartíneZ, A. (1993) Enfermedad, Cultura y Sociedad, Madrid.
} 
formal o convencional asumida por los Estados y delegada frecuentemente en las Organizaciones No Gubernamentales (ONGs) de desarrollo.

En el contexto urbano paceño han aflorado desde los años ochenta grupúsculos de médicos tradicionales y especialistas rituales indígenas de variada consideración. No significa que antes no los hubiera, puesto que la medicina popular aymara y quechua han tenido entre los residentes paceños una clientela segura hace tiempo; sin embargo ha sido de forma reciente cuando han aparecido sindicatos de yatiris en La Paz y El Alto que se dedican a tiempo completo a las atenciones ceremoniales y terapéuticas de su clientela urbana, generalmente residentes de adscripción indígena, extendiendo sus perentorios recibidores de nylon y cartón a modo de improvisados campamentos en las lomas y recodos de El Alto, en los sectores de «Faro Murillo» y «Sagrado Corazón», en las barriadas de Villa Dolores y La Ceja, así como en la zona del «Calvario» de Alto Villa Victoria. Lo cual no significa que en ciertos períodos del año, especialmente durante la víspera del primero de agosto, sean recabados con gran solicitud estos curanderos rituales indígenas, por parte de las élites criollas paceñas, para cubrir ciertas costumbres ceremoniales.

Junto a los yatiri aymara, existen en La Paz otros especialistas rituales y médicos considerados «naturistas», por su extenso conocimiento de especies herbáceas en los tratamientos terapéuticos que realizan. Proceden de la provincia Bautista Saavedra, con su capital Charazani, al Norte del Departamento de La Paz y a unos 200 km de distancia. Son los kallawaya.

Este artículo versa sobre las peculiaridades culturales de estos médicos indígenas oriundos de los Andes bolivianos y conocidos como kallawayas, término que se aplica en la actualidad al propio área regional del cual proceden. Las prácticas médicas kallawayas se nutren de una rica y variada farmacopea natural, un gran conocimiento de especies herbáceas, una medicina de rasgos rituales entroncados en una cierta afinidad «andina» que comparte con otras sociedades y grupos étnicos vecinos, (con ciertas peculiaridades diferenciadoras ) y una medicina popular de resabio hispánico que se plasma de una manera explícita en el entorno urbano de La Paz.

Los kallawayas han conseguido configurarse como interlocutores válidos frente al Estado boliviano en materia de salud, al conseguir su institución paceña, la Sociedad Boliviana de Medicina Tradicional (SOBOMETRA), reconocimiento presidencial a través de sucesivas resoluciones ministeriales y el beneplácito internacional en diferentes congresos sobre medicina natural.

Su lengua materna es el quechua, aunque conocen el aymara y el castellano y algunos utilizan destellos de una lengua ya perdida, el Machaj Juyay, según algunos especialistas emparentado con el pukina (Torero). Los kallawayas han conseguido superar barreras étnicas marcadas atendiendo a clientes aymaras y quechuas de diferentes sectores a los de su región de origen y encontrando sus prácticas médicas y rituales enorme eco en las élites paceñas quienes sienten predilección por estos médi- 
cos andinos, estudiados por antropólogos en las tres últimas décadas, lo que ha alentado en gran medida el mito del médico kallawaya itinerante y su resabio antiguo, vinculado, según algunos de los líderes actuales de la institución SOBOMETRA, con el propio poder del Inca.

Veamos quienes son los kallawayas y las peculiaridades del ejercicio de su medicina en La Paz. Para ello voy a utilizar el testimonio de Severino Vila, reconocido curandero kallawaya originario de Charazani. Su testimonio constituye una muestra de la opción que los kallawayas presentan en la ciudad de La Paz en términos médicos, junto a los yatiri aymaras y los representantes de la medicina convencional u occidental, sin menospreciar el desempeño de otros participantes en el mercado de la salud de La Paz como son los numerosos charlatanes de origen peruano que se reúnen en la Plaza de San Francisco vendiendo Uña de Gato 4 y paseando todo tipo de fauna exótica (serpientes, iguanas y armadillos) ante el regocijo de los viandantes.

No pretendo efectuar un análisis sistemático sobre las consideraciones sanitarias pluriculturales en la ciudad de La Paz; tampoco cargar las tintas sobre el enfrentamiento, la rivalidad o complementariedad existente entre medicina nativa y medicina occidental en poblaciones indígenas bolivianas, aspectos que desarrollo en otra parte ${ }^{5}$. En esta ocasión es el testimonio de Severino el que apunta hacia la opción concreta que los kallawayas y sus consideraciones culturales en torno a la enfermedad suponen en las prácticas terapéuticas efectuadas en una capital «moderna» como es la ciudad de La Paz y su vigencia resaltable en el acontecer urbano de los diferentes grupos sociales que la integran.

La práctica de la medicina indígena kallawaya en un entorno urbano permite plantear algunas reflexiones finales en torno al ejercicio de la interculturalidad en medicina y su aconsejable práctica entre poblaciones indígenas y agregados sociales culturalmente dispares. A contemplar este aspecto dedico el último capítulo del presente artículo. No adelantemos acontecimientos. Señalemos, en primer lugar, ¿quienes son los kallawayas?

\section{LOS KALLAWAYAS}

Uno de los grupos étnicos andinos a los cuales ha prestado una atención inusitada la ciencia antropológica contemporánea en relación con la medicina, el ritual y la salud en los Andes, ha sido, sin ninguna duda, el de los kallawayas bolivianos.

\footnotetext{
4 Uña de gato. Byttneria hirsuta, Según recoge el manual de GIRAUlT, L (1987) Kallawaya: Curanderos itinerantes de los Andes. Investigación sobre prácticas médicas, medicinales y mágicas, p. 310 , La Paz.

5 FERNÁNDEZ, G. (1997) «Que vaya pues chachawarmi». Enfermedad y cultura en el altiplano aymara de Bolivia, La Paz.
} 
Ubicados en una extensa área de valles interandinos, a medio camino entre el altiplano aymara y las tierras cálidas del trópico yungueño, puerta natural hacia los bosques y selvas del Beni, los kallawayas han practicado, como la gran parte de las diversas sociedades y pueblos de los Andes si bien en tonos diferenciados, una terapia médica peculiar, combinando aspectos provinientes de una amplia farmacopea popular con otros de indudable cariz ritualista.

Los kallawayas constituyen en la actualidad un espeso «enigma» tanto para etnohistoriadores como lingüistas y antropólogos. A pesar de los numerosos estudios de que han sido objeto por parte de especialistas de diversa índole, quienes han alentado cierto «orgullo étnico» entre los actuales kallawayas, así como un aire «exótico» y esotérico entre las élites paceñas respecto a los supuestos conocimientos «mágicos» que poseen, poco se conoce de una forma objetiva de este grupo de curanderos. El «mito etnográfico» de los kallawayas, como lo define Saignes, continúa envuelto en una bruma impenetrable ${ }^{6}$.

Las primeras descripciones etnográficas contemporáneas consideran a los kallawayas como una «clase rara» de indios acostumbrados a recorrer grandes distancias cargados con su capacho de remedios, por los pueblos del altiplano internándose hacia el Perú, Argentina e incluso se ha constatado la presencia de kallawayas en Panamá durante el período de construcción del canal ${ }^{7}$. Este carácter itinerante del médico kallawaya ha constituido un rasgo específico en su quehacer habitual hasta hace algunas décadas, circunstancia que ha despertado odios y asombro a lo largo de su camino. Para unos es un hechicero consumado, para otros un médico infalible. La figura del médico kallawaya levanta todo tipo de enfrentados comentarios a su paso ${ }^{8}$.

Es la práctica de la medicina natural a través de un conocimiento esmerado de especies herbáceas, el atributo identificativo del kallawaya. No comparto la opinión selectiva de Bastien ${ }^{9}$ quien distingue entre «adivinos» $\mathrm{y}$ «curanderos» en estos especialistas; un kallawaya conoce habitualmente las técnicas tradicionales de predicción, sabe curar utilizando mates y cataplasmas e igualmente practica los requisitos de la terapia simbólica mediante los pagos habituales a sus seres tradicionales utilizando

6 SAIGNES, T. (1983) «¿Quienes son los kallawayas? Nota sobre un enigma etnohistórico». Revista Andina, 2, 357-377;p. 372, Cuzco. Los mismos kallawayas urbanos de La Paz han configurado en su propio discurso una representación mítica peculiar sobre sí mismos y su entronque incaico peculiar, supuestamente justificativo de sus «poderes» y conocimientos. Ver, VuLPIANI, P. (1993) «Etnomedicina e sistema medico ufficiale in Bolivia. Il percorso storico di un gruppo di terapeuti itineranti delle ande boliviane:I kallawaya». Sociologia. Rivista di Scienze Sociali dell Instituto Luigi Sturzo, 389-422, Roma.

7 Ranaboldo, C. (1988), El camino perdido. Chinkasqa ñam armat thaki Biografía del líder campesino kallawaya Antonio Alvarez Mamani, p. 47, La Paz.

8 TERAN, L. (1955), «Los callahuayas, indios raros de Bolivia». Anuario de la Sociedad Folklórica de México, pp. 141-147;p. 142, México.

9 BASTIEN, J. (1982), «Exchange between Andean and Western Medicine», Social Science and Medicine, 16, pp. 795-803, p. 798 . 
formatos peculiares de ofrendas complejas, analizadas de forma exahustiva por Rösing ${ }^{10}$, que presentan una importante variedad y riqueza simbólica.

Los kallawayas son originarios de los valles templados que se localizan en las proximidades de la Cordillera de Apolobamba, en las provincias Bautista Saavedra y Muñecas, al Norte del Departamento de La Paz. Estos valles tuvieron una importancia estratégica relevante durante el Imperio Inca, por cuanto constituyeron la puerta de acceso a las tierras bajas amazónicas, lo que pudo incidir en el adiestramiento de los kallawayas en relación con el conocimiento de especies herbáceas y ciertos recursos «shamánicos» amazónicos ${ }^{11}$.

La presencia abundante de coca y oro en las tierras kallawayas intensificó el interés de los incas por estos valles, lo que, según ciertos autores, otorgó algunos privilegios a los kallawaya ${ }^{12}$. Por otra parte la pertinencia del oro y la coca en el ritual andino ha sido propuesto por Millones ${ }^{13}$ como un indicio de la especialización ceremonial que los kallawayas pudieran detentar entonces. Lo cierto es que los cronistas callan la supuesta especialización médica de los kallawayas, lo que junto a circunstancias de carácter ecológico, político y social sufridas por el área kallawaya durante la colonia, hacen del nomadismo terapéutico que les caracteriza un fenómeno tardío colonial e incluso republicano ${ }^{14}$.

La problemática «étnica» que los kallawayas concitan es igualmente importante. Por un lado, hablan el quechua, aunque conocen el aymara de los «vecinos» ubicados en las punas y tierras altas, así como el castellano con notable rendimiento. Oblitas ${ }^{15}$,

10 RöSING, Ina (1990b) Introducción al Mundo Callawaya. Curación ritual para vencer penas y tristezas. Cochabamba/La Paz, 1990b

RöSING, Ina (1991) Las almas nuevas del Mundo Callawaya. Análisis de la curación ritual callawaya para vencer penas y tristezas. Cochabamba/La Paz, 1991

11 Respecto a la ubicación estratégica de los valles kallawayas ver, SAIGNES, Th. (1983)»¿Quienes son los kallawayas? Nota sobre un unigma etnohistórico». Revista Andina, 2, 357-377;p. 362, Cusco.

WASSEN, H. (1988) «Instrumentos y plantas de un curandero indio en una tumba de la zona callawaya», Compilación de estudios sobre medicina kallawaya, 371-398, La Paz.

El término «shamán»o «chamán» tiene su origen en diferentes culturas siberianas, por lo que resulta inapropiado su empleo en los Andes, a pesar de las afinidades que la figura del maestro ceremonial siberiano pueda tener entre los grupos indígenas americanos, particularmente en lo que se refiere al viaje chamánico, los arrebatos extáticos y la ingestión de alucinógenos Al respecto ver ELIADE, M. (1975) Iniciaciones místicas, Madrid. Igualmente, ELIADE, M. (1993). El chamanismo y las técnicas arcaicas del éxtasis, México. Sobre el fenómeno del chamanismo en el altiplano andino, FERNÁNDEZ G. (1996a) «Sobre el éxtasis, el sueño y la oscuridad: Aproximaciones a las formas del viaje «chamánico» en el altiplano aymara». Revista del Museo Nacional de Etnografía y Folklore, 7, 49-74;p. 50

12 Llevar en «andas» al inca en tiempos de paz. POMA, F. G. (1615/1987) Nueva crónica y buen gobierno, Madrid, p. 332, 335.

13 Millones, L. (1983) «Comentarios», Revista Andina, 2, 378-379;p. 378. Cusco.

14 SAIGNES (1983), p. 369.

15 Oblitas, E. (1988), «La lengua secreta de los incas», Compilación de estudios sobre medicina kallawaya, 286-312, La Paz. 
Soria ${ }^{16}$ y un estudio póstumo de Girault ${ }^{17}$, reflejan la presencia de «otro idioma» característico de los kallawayas, el Machaj Juyay que algunos han identificado como «idioma secreto de los incas», o bien el idioma esotérico de las curaciones kallawayas y cuya naturaleza y origen están poco claros en la actualidad, si bien algunas hipótesis lo relacionan con el antiguo y extinto pukina ${ }^{18}$. La recopilación efectuada por Girault ${ }^{19}$ de la «lengua secreta» recoge la presencia de términos no sólo vinculados con las curaciones o la vida ceremonial, sino con aspectos diversos y «profanos» de la vida cotidiana. La confusión existente en las primeras narraciones sobre los kallawayas adscribiéndoles junto a sus vecinos como «aymaras» ha sido resaltada por Girault ${ }^{20}$, quien tampoco se compromete a ubicarles estrictamente como «quechuas» aunque esta sea la lengua materna que hoy les caracteriza.

Hay que añadir, además, la frecuencia del elemento «mestizo» entre los kallawayas itinerantes, fruto de sus uniones matrimoniales con mujeres de grupos étnicos dispares. Pese a todo, va abriéndose paso la consideración de los kallawayas como grupo étnico específico con una rica cultura material, especialmente relacionada con los textiles, a pesar de los numerosos rasgos culturales que comparten con otras sociedades andinas contemporáneas próximas a ellos ${ }^{21}$.

Existe otro aspecto que debemos considerar; los kallawayas propiamente dichos son los curanderos que proceden de seis pueblitos próximos a la capital provincial de Charazani. El resto, según Girault ${ }^{22}$, no pertenecerían propiamente al gremio de los curanderos kallawayas; los agricultores que no practican la medicina tradicional serían descendientes de los mitimaes enviados por el inca. Esta postura, sin embargo, tiende a remitir con la desaparición de la práctica nómada de los médicos kallawayas y se abre la consideración de un espacio o área kallawaya de significación propia.

Saignes ${ }^{23}$ muestra la unidad existente de lo que pudiéramos considerar «ayllu $\mathrm{ka}$ llawaya» repartido en dos parcialidades, una, la «alta», Hatun Carabaya, que resultó peruana y otra la «baja», la pequeña Calabaya, boliviana en los actuales valles de Charazani.

\footnotetext{
16 SORIA, L. (1988), «Pequeño vocabulario callawaya», Compilación de estudios sobre medicina kallawaya, 190-196, La Paz.

17 GIRAULT, L. (1989) Kallawaya. El idioma secreto de los incas, La Paz.

18 ALBÓ, X. (1989)»Introducción», Kallawaya. El idioma secreto de los incas, 13-17, La Paz.

ALBÓ, X. (1995) Bolivia plurilingüe. Cuadernos de Investigación CIPCA, 44, p. 124, La Paz.

TORERO, A. (1987), «Lenguas y pueblos altiplánicos en torno al siglo XVI», Revista Andina, 10, 329-372;p. 345, Cusco.

19 GiRAULT, L. (1989).

${ }^{20}$ GIRAULT, L. (1987) p. 27-28, La Paz.

21 GiSBERT, T. et al, (1987) Arte textil y mundo andino, 97-127, La Paz.

22 GiRAUlT, L. (1987). p. 24

23 SAIGNES (1983). p. 363.
} 
Vellard ${ }^{24}$ señala el encono y rivalidad que se produce entre los kallawaya y los yatiri, sabios aymaras; disputa, si cabe, incrementada en los últimos años. Resulta fascinante escuchar de labios de unos y otros los calificativos que generosamente se destinan. Los yatiri acusan a los kallawaya de «peseteros», «por plata no más trabajan», cuando no de causantes de daños y maleficios, mientras que los kallawayas que continúan practicando la medicina natural enclaustrados en el marco urbano de $\mathrm{La}$ Paz, en las próximidades de la Plaza San Francisco, orgullosos de sí mismos de una forma quizá un tanto faccionalista por su noble y supuesto «antiguo» saber, consideran a los yatiris como especialistas de rango y categoría inferiores. Los aymara recelan del kallawaya por su idioma y aspecto diferente, «qichua no más hablan esos», como me indica Modesto Capcha, yatiri de la zona alteña de Villa Dolores; los aymara siguen fieles a «sus» yatiri desconfiando del kallawaya, aunque las personas mayores de la comunidad refieren la visita de alguno de ellos, «de paso», si bien hace tanto tiempo que apenas nada queda en el recuerdo si no el trazo difuso de unas ujutas (sandalias) polvorientas. Curiosamente algunos equipos de salud que trabajan en zonas populares de la hoyada paceña, caso del barrio de Munaypata, me comentaron recientemente que personas de ascendencia aymara establecían una marcada diferenciación entre kallawaya y yatiri; si el caso requería el empleo de sustancias naturales y plantas acudían al kallawaya, si por el contrario la dolencia era más complicada y afectaba el interés de alguna de las entidades ceremoniales aymaras, consultaban al yatiri. El grado de confianza depende en el entremezclado dominio urbano, por tanto, de las peculiaridades concretas de cada caso, más que de apreciables diferenciaciones culturales o lingüísticas, sin menospreciar el hecho de que no todos los kallawayas hablan aymara, aunque lo entienden con razonable fluidez.

El conocimiento especializado de plantas es una de las características que otorgan una personalidad concreta al kallawaya. Girault ${ }^{25}$ catalogó mas de 800 especies diferentes empleadas en la farmacopea kallawaya. El interés de los kallawayas por las variedades específicas de las plantas, la diferenciación orgánica y terapéutica de las diferentes partes que la integran, (raíz, tallo, hojas y flores), los modos de recolección y empleo de cada uno de dichos principios (decocción, mate, infusión, cataplasma o enema) así como el cariz «cálido»o «fresco» del remedio, son factores importantes en la determinación que el kallawaya adopta en el tratamiento de la enfermedad ${ }^{26}$.

\footnotetext{
24 Vellard J. (1988), «Frente a la medicina moderna», Compilación de estudios sobre medicina kallawaya, 362-370, p. 366, La Paz.

25 GiRAULT, L. (1987).

${ }^{26}$ La medicina kallawaya considera la caracterización «cálido» y «fresco» de las enfermedades y la aplicación correspondiente de las especies herbáceas pertinentes, igualmente «cálidas» o «frescas», en la restitución del equilibrio térmico del organismo afectado. Estas cualidades térmicas presentan, en mi opinión, una relación unívoca con los principios de la medicina hipocrática que se incorporan a la medicina indígena y popular de América, tras la conquista española. Ver, Foster G M. (1980) «Relaciones
} 
Esta sabiduría aplicada a las especies herbáceas y remedios naturales otorgan al kallawaya un prestigio indudable en el entorno urbano paceño y constituye parte esencial de su aceptación como médico itinerante ${ }^{27}$.

Por otra parte el kallawaya es un maestro ceremonial excelente. Algunos kallawayas que residen en la ciudad de La Paz definen su competencia vinculada al área médica, pero también a la ritual. Se dicen «médicos» $\mathrm{y}$ «sacerdotes» de forma casi indiferenciada. El tratamiento ceremonial forma parte de la terapéutica kallawaya; su diversidad de aplicación depende de la etiología consignada a la dolencia del paciente. En este sentido, si bien las formas de ejecución ritual y las plegarias especialmente son kallawayas, al hacer referencia a lugares de poder ceremonial e intermediarios propios de aquel sector, comparten con otras sociedades y grupos étnicos andinos como los quechuas serranos, los aymara altiplánicos o los uru-chipayas lacustres, el gusto por la ofrenda compleja o mesa.

Las técnicas predictivas empleadas por los kallawayas en la formulación de sus diagnósticos médicos son diversas. Una de las más frecuentes consiste en la lectura de hojas de coca. Las hojas de coca adquieren sobre el tari ceremonial una disposición específica que el kallawaya interpreta en función de la textura, ductilidad, brillo $\mathrm{y}$ aspecto que las hojas presentan.

No existe una manera exclusiva o universal de lectura de la coca. Cada maestro ceremonial emplea la que más se ajusta a su capacidad y competencia. Es muy frecuente, no solamente entre los kallawayas, sino en el colectivo de sabios del altiplano y cabecera de valles andinos, considerar el valor cromático de la hoja. El haz verdoso y su envés blancuzco se conjugan para el análisis más pertinente del caso. Por otra parte, el kallawaya emplea las hojas de coca para escenificar diferentes cuadros alusivos a la naturaleza de la enfermedad, relacionada con los aspectos biográficos narrados por el paciente. Todos aquellos parámetros que el maestro kallawaya considere oportuno revelar durante la consulta a la hoja, adquieren forma narrativa merced a la utilización de ideogramas conformados con hojas que selecciona del conjunto total y sobre las que asperja, siempre con su mano derecha, las hojas restantes. El aspecto resultante de esta última acción sobre el tari ceremonial habilita al kallawaya para interpretar de forma más ajustada su análisis. La propia hoja de coca presenta una

entre la medicina popular española y latinoamericana». En, Kenny M. y DE Miguel, J.M. (eds. ) La antropología médica en España, p. 123-147, Barcelona.

La diferenciación «cálido» $\mathrm{y}$ «fresco» resulta frecuente en otras partes de los Andes en relación con la enfermedad. Ver, ORTEGA F. (1980), «La dicotomía caliente/frío en la medicina andina. (El caso de San Pedro de Casta)». Debates en Antropología, $\mathrm{N}^{\circ}$ 5, p. 115-139, Lima.

${ }^{27}$ Los especialistas rituales aymara conocidos como yatiri, «el que sabe», son particularmente valorados en sus comunidades altiplánicas. No acostumbran recorrer los caminos ofreciendo sus servicios, como al parecer era habitual en el kallawaya; sin embargo, los yatiri del altiplano ribereño a la hoyada lacustre del Titicaca, no dudan en incursionar los valles de Larecaja y Yungas cuando sus pacientes así se lo solicitan. 
estructura antropomorfa sirviendo sus nervaduras, variaciones de color y grietas para localizar el problema médico del paciente ${ }^{28}$.

Otra forma de diagnóstico utilizada por los kallawaya es el orín fermentado del enfermo. El orín provoca una reacción virulenta al mezclarse con millu o qollpa, sulfato de aluminio, que empleado como reactivo, produce una efervescencia espumosa susceptible de estudio y análisis ${ }^{29}$. Hay quien practica la «lectura de la vena», toma del pulso, y muy especialmente el análisis de las vísceras del cuy o conejillo de indias, una vez que se ha pasado por encima del cuerpo del paciente. La disección subsiguiente del animal muestra a los ojos expertos del kallawaya la localización del órgano dañado así como el origen del mal que padece su cliente. Estos recursos predictivos no son exclusivos de los curanderos kallawayas ${ }^{30}$. Finalmente, otra de las prácticas de diagnóstico que ha adquirido mayor vinculación con los kallawaya urbanos de La Paz es el empleo del naipe español.

La lectura del naipe, sin embargo, presenta ciertos rasgos peculiares propios del contexto andino en que se realiza su interpretación ${ }^{31}$.

La enfermedad es conceptualizada dentro de los cánones culturales kallawayas, compartiendo ciertos aspectos y formas terapéuticas afines a otras sociedades andinas, pero mostrando igualmente rasgos exclusivos de su propio entorno médico, farmacológico y ceremonial.

28 Ossio, J.M. (Coord. ) (1989), «Cosmovisión andina y uso de la coca», La coca. . . tradición, rito, identidad, 231-381, México.

${ }^{29}$ La capacidad de observación y análisis de imágenes y «figuras» constituye una práctica de interpretación y augurio frecuente en el altiplano. Las libaciones ceremoniales que se hacen con alcohol producen diferentes imágenes al empapar los papeles empleados como envoltorio de las ofrendas rituales; estas sinuosas imágenes son escrutadas con suma atención por los yatiri, puesto que contienen información alusiva a las peculiaridades del rito . De igual forma coincidiendo con las vísperas de San Juan (inicio del año nuevo aymara en el solsticio de invierno austral) es costumbre derretir plomo que se arroja violentamente sobre agua fría. La solidificación violenta del plomo produce una masa irregular plena de protuberancias y filamentos que el «maestro» ceremonial interpreta para aventurar la «suerte» del cliente. En relación con la lectura del orín, se produce una sugestiva analogía biológica. Si el orín «levanta», tras reaccionar con el millu, y forma figuras, suele contemplarse como augurio favorable; sin embargo, en caso de permanecer «plano», el pronóstico resulta desfavorable.

30 FRISANCHO, D. (1988), Medicina indígena y popular, p. 59, Lima.

${ }^{31}$ Las figuras del naipe español se interpretan en función de las peculiaridades del entorno y contexto kallawaya y «andino» actual en que se produce su consulta. Las imágenes se ajustan a la información otorgada por el paciente con ciertas características peculiares. Existe una indiferenciación marcada de género en el reconocimiento de reyes, caballos y sotas, cualidad característica de las lenguas andinas y relativa a las confusas imágenes que la alteridad produce. Las copas se relacionan con el «trago» y los conflictos que suele propiciar, las espadas con la justicia, y los bastos, particularmente el tres y as de esta mano, con la brujería, que en el contexto kallawaya así como en el aymara, aparece vinculada con la presencia de astas y espinos. Las barajas españolas son deseadas por su poder excepcional, siguiéndose para su uso, pasos previos semejantes a los empleados en relación con el tratamiento ceremonial del tari y las hojas de coca. 
El testimonio que a continuación presento constituye un breve extracto de las numerosas conversaciones mantenidas por espacio de varios meses con un maestro kallawaya en la ciudad de La Paz. Severino Vila es natural de Charazani, capital de la provincia Bautista Saavedra del Departamento de La Paz; su familia procede del pueblito de Chajaya en las proximidades de la región dominada por las alturas de la cordillera de Apolobamba. He sido ayudante suyo en alguna de las atenciones médicas y ceremoniales que realiza en La Paz y viajé con su familia a los recónditos valles kallawayas coronados por la imponente figura del nevado Akamani. Severino es médico kallawaya y se encuentra afiliado a SOBOMETRA, Sociedad Boliviana de Medicina Tradicional, en la ciudad de La Paz. Esta institución aglutina a cerca de 40 médicos kallawayas, residentes en La Paz, que ejercen sus conocimientos en las inmediaciones de la calle Sagárnaga, cerca de la plaza de San Francisco. Indudablemente es un colectivo habituado al trato con los «residentes» urbanos de extracción indígena y con las diferentes clases y grupos sociales que integran la colectividad paceña.

Severino acompañaba a su padre, siendo apenas un niño, en los viajes que realizaba a los valles cochabambinos practicando la medicina tradicional. Aprendió con su abuelo, natural del pueblito de Kanlaya, el arte de la medicina kallawaya incluyendo un conocimiento minucioso de especies herbáceas y talismanes ${ }^{32}$.

Cuando era apenas un joven adolescente continuó en compañía de su hermano menor practicando la medicina itinerante que podía hacerlos demorar más de mes y medio en su retorno a Chajaya, portando los bienes y el dinero conseguido mediante el ejercicio de las prácticas terapéuticas. Severino tuvo una adolescencia complicada; los problemas habituales en el hogar paterno le obligaron a abandonarlo pronto, pasando a desempeñar ocupaciones dispares al margen de sus conocimientos como incipiente naturista kallawaya. Finalmente, Severino abandonó el oficio de relojero que había aprendido después de realizar el servicio militar en Caranavi, localidad de la provincia Nordyungas, para retornar de nuevo a La Paz y practicar la medicina kallawaya tal y como su abuelo le enseñó.

Después de treinta años de experiencia realizando esta función como médico, naturista y especialista ritual, el testimonio de Severino constituye un reflejo fiel de las conceptualizaciones indígenas kallawaya respecto a la etiología de la enfermedad y su tratamiento, con ciertos resabios de sofisticación urbana.

He preferido mantener el estilo expresivo propio de Severino incluyendo las notas de pie de página pertinentes para la mejor comprensión de sus palabras; en ellas se combinan recetas y plantas con fórmulas cosmológicas, farmacopea y plegarias con

32 La elaboración de talismanes en miniatura, tallados en diferentes tipos de piedra y yeso constituye una de las técnicas ceremoniales relacionadas con las prácticas kallawayas. Ver, GIRAULT, L. (1987), p. 543-618. OBlitas, E. (1978), Cultura callawaya, La Paz, p. 223-230. 
ungüentos, cataplasmas y ofrendas. Todo este complejo marco de elementos conforma la urdimbre que sostiene el modelo estructural integrador de las prácticas médicas kallawayas.

La primera parte del estudio está dedicada a la información presentada por Severino en relación a las formulaciones y recetas médicas, incluyendo algunos referentes de especies herbáceas, farmacopea, propuestas dietéticas y prácticas ceremoniales. El segundo apartado lo refiero exclusivamente a las ofrendas rituales complejas denominadas, mesas. Uno y otro aspecto reflejan las áreas de competencia médica del kallawaya así como el talante y la caracterización peculiar que adquiere su figura; por otra parte las técnicas y recursos empleados por el kallawaya en el tratamiento de diversas enfermedades, aflicciones y dolencias, permite aproximarnos a la naturaleza explícita de cada afección recogida por Severino, a su etiología particular, así como a las estrategias terapéuticas recomendadas.

\section{EL TESTIMONIO}

«Yo soy de la localidad de la Provincia Bautista Saavedra, de Charazani, capital de la medicina. Kallawaya, Severino Vila. Yo soy de mis abuelos, de mis tatarabuelos. Soy kallawaya nativo y mis abuelos me enseñaron diferentes clases de hierbas para atender a la gente pobre y nos viajábamos a los campos a diferentes lugares hasta diferentes departamentos curando a las gentes. Viajando lejos, cargando nuestras camitas, nuestras ch 'uspitas, con nuestro botiquin ${ }^{33}{ }^{\prime}$.

«Llevamos nuestra medicina molida y, a veces también, a veces, muchas veces sufrimos también en los caminos. No hay comida, muchas veces, no hay agua el sol, o nos hace pasar frío. ¡Tantas cosas nos ha pasado! Pero hoy adelante tenemos una institución, la Sociedad Boliviana de Medicina Tradicional, SOBOMETRA. Estamos en La Paz, Departamento de La Paz estamos».

«Cuando tenía 12 años ya estaba empezando, cuando viajábamos a Cochabamba a Santa Cruz también a Muruchata, después Quillacollo. . . ¡Todos los sectores! Potosí salíamos hasta Oruro caminando ¿no? Los kallawayas habían sabido caminar lejos; un mes perdía casa por casa, con medicina andábamos. Llevábamos medicinas para el «aire», para reumatismo, para la katxa, para matriz ${ }^{34}$, llevábamos

\footnotetext{
33 Ch'uspa:Pequeña bolsa tejida que se emplea para llevar hojas de coca.

34 Diferentes síndromes culturales identificados por los kallawayas, pero que no resultan exclusivos de ellos, localizándose en distintos sectores de los Andes como lo atestiguan entre otras las siguientes referencias etnográficas, PALMA, N.H. (1978), La medicina popular en el noroeste argentino, Buenos Aires. LiRA, J.A. (1985), Medicina Andina. Farmacopea y Ritual, Cuzco. Aguiló, F. (1985), Enfermedad y salud según la concepción aymaro quechua, Sucre.
} 
medicamento, entonces mayor parte gentes se enferma de matriz, de los riñones, reumatismo. . . Eso mayor parte sufre la gente».

«Hoy adelante ya no caminan; los demás están yendo a las provincias los demás, pero nosotros ya estamos en ciudad, pero así mismo estamos rondando a otros departamentos. Estamos llegando a la Argentina, estamos llegando a la Brasil, estamos llegando. . . jdiferentes lugares!».

«Así a diferentes lugares llevan a los sacerdotes a los kallawayas, a los médicos kallawayas. Somos médicos, atendemos toda clase de enfermedades, de los ataques, de las pulmonarias, de las bronquitis, pero también atendemos de la matriz, o también puede ser del dolor de cabeza, puede ser ardor de manos, los pies jhay forma de curar!, hay forma de atender puro a base de hierbas. Hay hierbas bastantes aquí; bastantes medicinas veo. Ustedes no conocen. En Bolivia, ¡más mejor! Muchas plantas hay en Bolivia, todo es la medicina. . . . iTodo! Hasta de un barro, hasta. . . una piedra macho es medicina, hasta el fierro. . . ¡hasta nuestro baño es medicina! iEs gran medicina! Eso hay que conocer, hay que analizar de poco a poco las hierbas, nuestro cuerpo mismo podemos hacer, pero poco a poco no a golpe, eso debemos saber».

«Debemos cuidarnos nuestra salud, nuestra planta jAquí está! lo estamos pisoteando. . . . ¡no es así no más! Debemos analizar ¿para qué es? Así poco a poco vamos a saber, vamos a dar un tratamiento. . gente pobre se toma. Analiza nuestro cuerpo mismo. Una planta veo. . . pino en La Paz. Ese pino sirve para dolor de estómago, tomar poquito, no siempre una rama, será una puntita, será una ramita. . . poquitito, circula como infusión, lo tomas matesito ¿cómo te hace? voy a analizar en ese caso».

«La medicina es para todo, para cualquier enfermedad, pero hay que saber, hay que preparar bien, hay que tomar. Vayamos hablando. . . de los «sustos» 35 .

«Hay muchas veces personas tenemos poco ánimo, pero. . . . no tenemos fuerza, muy débiles somos. . . para poquito. Si alguien le ve. . . un perro se acerca. . . «ipucha, me va a morder!», se asusta uno. Uno se pone nervioso, no quiere comida, no tiene sueños en las noches, fatiga y levanta. Ese es «susto». Entonces nosotros agarramos una flexión en el cuello, los brazos estirar arriba, los cruzados hacer cuestión de jalón, los brazos, los corazones nivelarlo y sacudirlo así en esa forma a la persona. Frotarlo la cabeza, atrás un jalón de cabello ;Kaj! Escupe la persona que está asustado, escupe tres veces, escupe. Ese es la gente. . . jsano! Ya come la gente.

$35 \mathrm{El}$ «susto» es un síndrome cultural que puede localizarse no sólo en las sociedades andinas, sino en otras poblaciones indígenas y mestizas de Latinoamérica. En los Andes, el susto viene propiciado por una fuerte impresión que desencadena la pérdida de una de las entidades anímicas que conforman el alma humana. Ver, RuBEL, A.J. (1986), «El susto en Hispanoamérica». Arinsana, 1, Cusco, p. 29-42. 
.. ipucha! sencillo, no necesita q`uwa ${ }^{36}$ ni sullu ${ }^{37}$ ni coca. Es fácil. Ese debían hacer. Debemos saber, debemos aprender más, debemos capacitarnos más. Ese debemos prepararnos nosotros, porque nuestros abuelos nos enseñaron. Después hemos sabido distintas formas de preparaciones, distinta forma de curaciones».

«Y, llamar ánimo. Puede ser también, podemos llamar ánimo. Uno puede ser con coca, coca no es cocaína ${ }^{38}$, coca es, medicina para cataplasma, para varias cosas» .

«Llamar ánimo, coca, q`uwa, incienso, copal clavel y un poco de azúcar, poquito. . . esa cantidad hay que colocar. Luego con alcohol ch allar ${ }^{39}$ «que venga su espiritu, que venga su animu, venga su espiritu, jte llamo!, venga, venga, venga», con su ch ‘uspita, con su camisita, con su gorrito, por lo menos puede ser, podemos llamar ánimo. Llamamos animito, «ánimo, ajayu venga, venga, venga, espiritu venga, venga, te llama, tu ánimo, tu ajayu, venga». . . . con campanita «Chililín, chililín» «ya,

36 Wira q'uwa. Senecio mathewsii. Especie herbácea aromática silvestre, propia de los sectores de altura. Localizada por GIRAULT (1987), p. 486. en las inmediaciones del abra de la cumbre, por encima de los 4.000 metros, puerta de acceso hacia el trópico yungueño. Especie caracterizada por su inclusión en gran cantidad de preparaciones rituales y mesas.

37 Sullu. Feto de animal. Se emplea en las elaboraciones rituales y ofrendas complejas. El más considerado en las ofrendas a la tierra es el feto de llama (qarwa sullu), si bien, según el tipo de elaboración ritual, se utilizan otras especies como el feto de cerdo y el de oveja. Sobre las caracterizaciones de los fetos y su empleo en las ofrendas rituales altiplánicas ver, FERNÁNDEZ, G. (1993), «Sullu, mesa y lógica social aymara», Revista de Dialectología y Tradiciones Populares, Tomo XLVIII, p. 85-115 Madrid

38 Existe una importante sensibilización social en Bolivia en relación con la problemática de la coca surgida con respecto al empleo de la hoja en la elaboración de «pasta base» para la producción de cocaína y su posterior vinculación al tráfico de estupefacientes. Esta dura pugna entre productores de hojas de coca y consumidores de cocaína, mayoritariamente extranjeros que se deben a círculos extensos de consumo dominado por las mafias internacionales, no ha pasado inadvertido a los grupos indígenas; por un lado en defensa de los derechos al consumo tradicional de hojas de coca, considerado un bien cultural de indudable aprecio en las sociedades andinas, por otro en relación con los problemas que está suscitando entre los productores de coca, fundamentalmente campesinos indígenas del área yungueña y del Chapare cochabambino, la actuación estadounidense en la lucha por la erradicación de cultivos. La diferenciación entre coca para usos tradicionales y lo que se ha venido en llamar «coca excedentaria» para la elaboración de «pasta base» en la región del Chapare, canaliza en gran medida la política de erradicación de cultivos del gobierno boliviano a inspiración de la administración Clinton. Sobre los usos culturales de la hoja de coca en las poblaciones aymara de Bolivia ver, CARTER, W. y MAMANI, M. (1986) Coca en Bolivia, La Paz.

${ }^{39}$ Ch'alla. Libación alcohólica. Consiste en una simple aspersión del líquido, generalmente con el dedo índice de la mano derecha, con la intención de convidar a los diferentes seres tutelares que son recordados por el oficiante durante una ceremonia. La costumbre de la ch'alla se ha generalizado en cualquier acontecimiento social que se efectúe. Antes de servirse el primer trago, es preciso que los seres tutelares del entorno beban primero, razón por la cual se vierten algunas gotas en su honor. La ch'alla aparece como institución social y ceremonial en diferentes sectores de los Andes. 
¡listo!» ${ }^{40}$. Ya la persona se pone, la persona que está asustada, está durmiendo. Nosotros le damos matesito, toma ese matesito, la mitad se lava sus manitos, la carita, los pies y luego a acostarse. . . ya, tranquilo. Ese se llama llamar ánimo. Ese se llama curar;en esa forma se cura la animu».

«Ahora podemos pararnos en hemorragia. ¿Por qué tiene hemorragia? puede ser también, hay muchos casos puede ser de rayo o puede ser también por la mala caída o por calor. . . o también puede ser por frío. Entonces nosotros agarramos cuando hemorragia le da a la señora o al hombre. . . . muchas veces hemorragia de nariz le bota entonces. . . . donde el médico no curan eso. Nosotros curamos. Nosotros nunca hemos conocido los médicos. Así nuestra tradición, nuestros medicamentos, nuestra hierba y curamos nosotros, cataplasma de la media espalda con trapo negro; primer lugar le remojamos en orín el trapo, ¡nuestro orin es medicina! Le remojamos biensito, le exprimimos, sacamos todo el zumo y le colocamos a la media espalda con trapo mojado. El persona ya no tiene esa hemorragia, lo que bota. . . . iya no tiene! Eso basta».

«Ahora otro caso, puede ser del Señor, de relámpagos, de lo que llega, asusta a uno, a alguna persona, alguno de sus familiares le ha asustado, relámpagos, por esas razones a veces uno se siente susceptible, cabeza duele, mareo o sea, no tiene ganas y le bota la nariz sangre. Bota, bota, bota. . . « ¿Qúe puedo hacer?». Eso es del Señor».

«Hay que alzar con inciensito, con braserito decir. . . «Señor tata Santiago, tata San José, tata San Juanito. . . ison malos a veces esos rayos! ${ }^{41}$. Esos hay que darle

$40 \mathrm{El}$ alma de los seres humanos está configurada por una diversidad de instituciones anímicas. Aja$y u$, «animu», «coraje» son las tres principales, si bien podemos encontrar otras denominaciones como «ispiritu» e incluso «santo» o «angel de la guarda».

41 El rayo es una de las entidades religiosas de mayor impacto e importancia ceremonial entre las sociedades andinas. Se constituye en elector de especialistas rituales; él «golpea» a sus candidatos obligándoles a comprometerse en el ejercicio de su desempeño ritual, así lo testimonian diferentes fuentes etnográficas (TSCHOPIK H. (1968), Magia en Chucuito. Los aymaras del Perú, p. 195 México. HARRIS, O. y BOUYSSE-CASSAGNE, T. (1987) «Pacha:En torno al pensamiento aymara», Tres reflexiones sobre el pensamiento andino, p. 46, La Paz. HuAnCA, T. (1990), El yatiri en la comunidad aymara, p. 69, La Paz. RösING, I (1996b) El rayo, amenaza y vocación. Creencia y ritual en los Andes bolivianos, Ulm). Los rayos son identificados como «visitas» a las cuales hay que tratar con la correspondiente cortesía, como es usual hacer con las visitas que llegan inesperadamente a los hogares. Estos rayos son objeto de culto en los lugares donde se atestigua el impacto producido con la tierra. Es frecuente que se levanten altares o «calvarios» como testimonio de dicho encuentro. Por otra parte los rayos poseen diferente talante y carácte; existen rayos buenos y rayos malignos. Los kallawayas atesoran peculiares formas de relación con los rayos a través de plegarias que reflejan el especial contexto del valor ceremonial que se le concede. Ver RösING I (1989): 3-34 «Lightning from the Upper-Earthand Darkness-World. An Andean Healing Ritual for Being Struck by Lightning», REVINDI. Revista Indigenista Latinoamericana, 4, p. 3-34, Budapest. Rösıng, I (1995b) Diálogo con divinidades de cerros, rayos, manantiales y lagos: Oraciones blancas kallawayas, La Paz. 
una ofrenda, la mesa blanca, hay que alcanzárselo «tata Santiago, perdoname, disculpame, te lo estoy convidando", diciéndole hay que ofrecerlo al Señor, darlo una mesa. Así, entonces se levanta con incienso se alza al Señor. . . . jme quedo tranquilo!, diciendo. También puede ser la piedra del rayo. Hay muchas veces, tiene dos colores, otro negro, otro rojo; hembra y macho. Tamaño. . . ese tamaño; y rasparlo con agua bendita, raspar poquito su sangre. Sobre ambas piedras rasparlo. . . sangre llora de la piedra del rayo. Entonces en vino de. . . . ino es vino! agua bendita hay que hacer tormar reposadito en tutuma ${ }^{42}$, tutuma o jarro ;lo que sea! Ponerlo el agua bendita, después emplear el clavel, después emplear ese raspado de aquí, junto con agua bendita hay que regar así. Incluirlo, ampliarlo luego, los misterios ${ }^{43}$ que hay, misterios del Señor, formado del Señor, tata Santiago, Virgen de Copacabana, Virgen de. . . itoda clase!».

«Entonces también itodas las vírgenes! también hay que molerlo, hay que incluirlo en ese jarro. Moverlo todo, en ayunas debe tomar todito, con flor reposadito así en agua bendita no más. Blanco, puro blanco, nada rojo. Tomarlo siempre, insiensito hay que alzarlo, hay que sahumear. El enfermo. . . . iya no tiene hemorragia!».

«También podemos hacer cambio con cataplasma con conejo blanco. Porque hay que limpiarlo cataplasma de la nuca. Limpiamos con incienso, con copal, así igual también limpiando, le botamos medio camino».

«Eso se llama «cambiar del Señor», hacer para la mesita con incienso blanco. . . ¡en fin! Eso se llama curar del rayo. Por eso sale la hemorragia. . . son ;dos cosas!».

«Ahora, caso de la mujer, caso de la mujer. A veces, muchas veces, también en la mujer se asienta la hemorragia. Botan por orinar como sangre. ¡Aggg! Bota harto. Entonces decimos. . . ¿Qué tienes señora? Por qué corre también. Uno se asusta, uno se admira. . . . «No sé». . «¿Qué puede hacer uno?». No sé qué hacer no puede. Para eso hay que curar chakana negro ${ }^{44}$, hueso del suri ${ }^{45}$, su pluma y también alquitrán. También es bueno, también. . . . eso sería otro, sobre eso complementaría phu$k a$ de punta ${ }^{46}$ iPucha! ese es única planta, se emplea unito, solito hay que hacer tomar. Cinco litros preparamos, todas las mañanas se puede tomar. Ese totalmente corta. . . YYa no tenemos hemorragia! Ahora si no le corta eso, podemos preparar. ..,

42 Tutuma. Pequeña calabaza de la zona tropical empleada como recipiente para líquidos

43 «Misterios». Pequeñas galletas rectangulares efectuadas con una mezcla de azúcar y cal que contienen gráficos en bajo relieve, alusivos al carácter de la ofrenda en la que entran formando parte del conjunto de dulces y alfeñiques que pueden adquirirse en los mercados ceremoniales y ferias campesinas (jampi qhatu) MARTíneZ, G. (1987), Una mesa ritual en Sucre. Aproximaciones semióticas al ritual andino, p. 25, La Paz.

44 Chakana negro. Chiyara Chakana (Urtica magellanica).

Especie localizada en los valles altos de La Paz. GIRAULT (1987), p. 160

45 SuRI. Nandú (Rhea Americane). GIRAUlt (1987), p. 500

46 Phuka. (Laccaria sp). GIRAULT (1987), p. 99 


\section{GERARDO FERNÁNDEZ JUÁREZ}

es que es cosa cálida, la chankaka es cálido, pero a otro metemos cosa fresca. La fresco es un barro bien cernido, barro hediondo, estuco batido con orín, nuestro orín. Batirlo como para revocar la casa. Entonces agarramos, ya está batimos, luego le colocamos cataplasma altura de la cintura. Ya con eso ya está, en fin, sanita la señora, ya no tiene hemorragia y otra cosa hemos hecho. Por calor, por frío. . . . Calor la medicina le damos, no le hace entonces con la frío también hay que meterlo, cosa fresca. Relaja totalmente. Lo que sé, lo que he curado estoy hablando. Eso sería de curaciones. . . hemorragia». También puede ser el mareo. El mareo viene muchas veces, puede ser por debilidad, también preocupaciones o preocupado, tiene algún problema el señor, o mala alimentación. Tiene problema. Piensa, piensa. . . Uno quiere dar como arrinconarse, quiere caerse, no tiene ganas, no tiene voluntad, quiere dormir, pensativo. Mucho piensa, por eso ataca a los corazón. Por eso mareo, tanto pensar, tiene mareo. Para eso la medicina hay. Estamos sobre la planta. La medicina, mar de estrella, hembra y macho ${ }^{47}$, la mitad quemadito, la mitad sin quemadito, puro un pedazo, no es necesario grande. Sigue empleando. . . también puede ser la murciélago, también quemadito, la mitad sin quemadito. Sigue nuez moscada, puede ser la waji $^{48}$, puede ser chichi ${ }^{49}$, puede ser también castilla ruda ${ }^{50}$, puede ser ruda. También se emplea para todo esto alcanfor pasta también. Pasta en la farmacia, de químicos siempre. Entonces, todo eso molerlo y hacerlo madurar, la mitad de botella de vino o singani ${ }^{51}$, echarlo molido todas esas cosas que requemadito.

«Todo hay que hacer madurar, eso lo que va a moler hay que emplearla con la mitad de la botella hay que emplearla al singani o si no es vino. . . ilo que sea! Tiene que madurarse una semana. . . menos, unos tres días, cuatro días. . iya, listo! Cada mañana debe tomar poquito, un vasito, una copita, hora de las doce, una copita, chiquitito, no es necesario un gran vaso, copitas. Tarde, para dormir, también. En la mañana, en la tarde, en la mañana, en la tarde debe tomar eso, ¡nada más!Eso es para ataque cardíaco. Para eso es eso».

«Ahora, uno tiene preocupaciones también, mismo caso, casi, casi, linaza con waji. Por ejemplo, a veces preocupaciones no faltan no faltan ¿no? A veces me preocupo, pienso. . . tomo linaza con mi wajito, con eso no más camino, con eso ya. . . ¡listo!»

47 Estrellamar femenino (Stichaster aurantiacus Meyen) de cinco puntas y estrellamar masculino hembra (Heliaster heliantus lamarck) de 30-32 puntas. GIRAULT (1987) p. 519. Se emplean igualmente formando parte de las mesas rituales, particularmente las mesas negras (c'hiyara misas).

48 Waji (Aristolochia fragantissima). GIRAULT (1987), p. 165

49 Chichi chichi (Chersodoma jodopappa). GIRAULT (1987), p. 474

50 Ruda (Ruta graveolens) Especie silvestre en las alturas de La Paz (3.600 metros). GIRAULT (1987), p. 272.

51 Singani. Bebida alcohólica semejante al aguardiaente, pero más refinada. 
«El kharisiri es muchas veces. . . voy a hablar de los kharisiri, vive en valle, en trópico. Ellos son sacerdotes del padre, padres son esos ${ }^{52}$. Tata cura dicen, padre de la iglesia ¿no? Eso son ellos, pero me contaron mis padres, pero no sé, nunca no le he visto, pero he sabido, me han contado así, mis abuelos, mis papás, por eso he sabido. Dicen que se ha hecho kharisir, dicen que tiene, así dicen que anda, pero sí dicen que le había pillado. Algunos cuentan, me contaron también. . ¿ ¿no?».

«El kharisiri tiene su presión. . . . iphucha! muy caloraso siente. . . calor, tiene diarrea, no tiene valor ${ }^{53}$, en la cama se acuesta, ya no se puede levantar más. Para eso nosotros, icosa sencilla! No es mucho. Podemos preparar grasa o una oveja negra. Agarramos, rápidamente, el panza le abrimos, la grasa, lo que complementa a la panza, su grasa ese hay que sacar, su telita y todo. . . lik ‘ decimos nosotros en quechua. Entonces eso «k`aj» colocando «aquí me duele», k`aj le hacemos colocar, después huevo batido blanco no más, también puede ser eso, también puede limpiar con los cuatro huevos o también puede tomar, tomadito un huevo, pero sin azúcar nada, eso se llama curación de los kharisiris. Estos temas raras veces me llegan, pero nuestros abuelos nos contaron. Esas cosas, si, una vez cada unos cuantos años, una vez escuchamos; a los dos años. . juna vez! Así pasa. Hay también otra forma. Prepara habas rojo, sebo de llama, su líquido que bota se prepara».

«Se hace madurar, toma, toma, también ya no se coloca, pero más que todo es la grasa, grasa de oveja aplica. Eso hay que emplear donde está doliendo, o si no es huevo batido, pero no avisarlo al personal que está enfermo. Si avisamos ise asusta peor! ¡Ya me voy a morir; ya no voy a vivir, estoy mal!, en fin ya problemas puede haber o peor causamos. Mejor es que secretamente hay que curar esas cosas».

«El arco iris, en campo siempre estamos donde hay lugar filtrante, el agua y llueve y sale el sol. Se forma arco iris donde sale del agua. Se forma arco iris. La

52 Kharisiri. Personaje maléfico que recorre los caminos interesado en robar a sus víctimas grasa del costado y sangre. Este peculiar «sacamantecas» andino se encuentra en las regiones altas de Bolivia y Perú recibiendo diferentes denominaciones (ñaqaq, phistaco, sacaojos, lik'ichiri, khariri). El comentario de Severino engarza con las versiones más tradicionales donde se relaciona la actuación del kharisiri con el «tata cura», el sacerdote y sus secuaces. Ver al respecto las siguientes referencias: ANSIÓN, J. (1989) (Edit. ), Phistacos, de verdugos a sacaojos, Lima. MOROTE, E. (1988):153-177, Aldeas sumergidas. Cultura popular y sociedad en los Andes, p. 153-177, Cusco. FERNÁNDEZ, G. (1996b), «El mundo «abierto»: Agosto y Semana Santa en las celebraciones rituales aymaras», Revista Española de Antropología Americana, 26, p. 205-229, Madrid. En otras versiones que he recogido sobre el kharisiri en el dominio aymara se le achaca la extracción de la grasa de los riñones, existiendo diferentes procedimientos para curar al enfermo quien, en cualquier caso, nunca debe conocer el origen que se otorga a su dolencia.

${ }_{53} \mathrm{La}$ supuesta pérdida de sangre o grasa recluye a la víctima en su casa. Pierde el valor, el principal recurso energético y vital que posee la vida humana representado en la gordura, la grasa y la sangre. Con referencia a la importancia simbólica de los fluidos humanos en los Andes ver: SZEMINSKI, J. (1987), Un curaca, un dios y una historia, p. 13, San Salvador de Jujuy. BASTIEN, J. (1986), «Etnofisiología andina. Evidencia Lingüística, metafórica, etiológica y etnofarmacológica para conceptos Andinos sobre el cuerpo». Arinsana, 1, 5-24, p. 12, Cuzco 


\section{GERARDO FERNÁNDEZ JUÁREZ}

persona, ese agua, por ahí está. . jle toma! ese agua. Cuando se ha levantado arco iris, se ha levantado arco iris él está tomando ese agua. Entonces, por esas razones, cuando ha tomado agua, él jotra clase se siente! Ya poco a poco, ya más infla la barriga igrande! como si puede estar esperando familia. Las manos moradas, la barriga grande «Ay. ¿ ¿qué pasa?» «Porque ese agua no más he tomado». Ese arco iris, se puede curar. Con floripondio ${ }^{54}$ le hacemos infusión, biensito las flores recogemos, no importa las hojas más. Ponemos cataplasma donde está inflamado. Amarramos con fajita ancha. Luego, doce colores de lana o también puede ser doce colores de sebario ${ }^{55}$, en Perú hay ese sebario. Le hacemos agua hervida infusiones, agua hervida le hacemos infusiones y le hacemos tomar. Esa persona. ... relaja».

«También puede ser del chancho su huevo, o su pelo o su orín, de color rojo chancho o si no es amarillo. Ese es muy grande medicina. Yo ya he analizado bastante. ¡Pucha! con orín, cuando está el chancho, está orinando hay que ir a aprovechar, hay que recibir y así toma el persona, toma. Lo demás se lava su mano si está inflamado ¡Pfiuиuи! ya no hay hinchazón, relajamiento. Orín, normalmente orina. Ya no hay esa inflamación. Eso es arco iris».

«La anemia. También hay muchas veces la persona duerme, duerme no tiene ganas de comer, poco come, duerme, poco come, duerme, no quiere trabajar. En la cama no más está durmiendo. Sus papás, sus mamás se reniegan, «este mi hijo muy flojo es», no tiene ganas, muy pálido, amarillo. ... no tiene valor. Sigue en la cama. Parece que la cama no puede dejar y amarillo. Ese es anemia. Ese es por debilidad, viene eso. Para eso hay que emplearlo el fierro que está oxidado raspado con una cucharillita, con alguna forma hay que sacarlo el fierro oxidado. Medio cafecito es ese color, rasparlo y un jarro ponerlo y agua hervida echarlo, infusiones darlo, hacer tomar eso. Ahora, si no le hace bien entonces hígado de la vaca, hígado de vaca cortajeadito un pedacito como un tamaño de un huevo, esa cantidad bien cortajeadito, un vaso de bicervecina negra ${ }^{56}$ después licuar».

«En ayunas hay que hacer tomar. Ya persona está consciente ya ipucha, carajo. ...! Siempre hay que dar alimento, cosas, alimentos, puede ser pata de ganado, puede ser nervio de ganado, puede ser también leche o frutas o pescados. Eso corrige toda clase de enfermedades. De lo que sé estoy hablando; eso sí se cura. En esa forma ese tratamiento se hace».

\footnotetext{
54 Floripondio (Datura arborea). GIRAULT (1987), p. 383. Planta con propiedades alucinógenas. Frecuente en los Yungas, en las cabeceras de valle (3.400 metros) y en algunos recovecos protegidos del altiplano lacustre del Titicaca (3.800 metros).

55 Sebario (siwairu) (Hematita pulverizada. Oligisto micáceo). GIRAULT (1987), p. 530. Suele tratarse de polvos de diferentes colores con matices diferentes, generalmente doce, que provienen de distintas sustancias (plombagina en polvo, oligisto micáceo, almidón de arroz. . . etc). Otras referencias sobre los sebarios encontramos en FrisAnCHO, D. (1988) p. 76, Lima. GIRAULT, L. (1988), Rituales en las regiones andinas de Bolivia y Perú, p. 234, La Paz.

56 Cerveza de malta.
} 
«También puede querer hacer a la pachamama, a la santa tierra, tierra virgen, nuestra costumbre es en Bolivia. Para las empresas, para la mina, para las empresas de estaño, para el oro, la plata, para construcciones nosotros ofrecemos a la madre tierra. Nos da plantas, nos da agua, nos da oro, nos da estaño. Porque. . . iQueremos a la pachamama! No es que no. . i iqueremos! Podemos ofrecer con un gallo rojo, también podemos ofrecer con feto de llama, o también podemos ofrecer con toro o también podemos ofrecer con chancho. La chancho es plata, el toro es mujer, el gallo. . . igallo rojo! es de la pachamama, como un cariño, como si le podemos dar un saxta ${ }^{57}$, un thimpu ${ }^{58}$ un comida buena, le invitamos. Diciendo preparamos todo completo las preparaciones; unas ocho o diez cosas entran. Preparamos todo con Madre Tierra, pachamama «pachamama yo te ofrezco con cariño con corazón, con voluntad. Dame valor, dame capacidad, dame fuerza y ánimo. Con todo mi cariño te ofrezco pachamama. Señor pachamama ${ }^{59}$ yo te ofrezco esta ofrenda, dame valor, dame capacidad dame inteligencia, dame salud, dame buenos viajes. . . todo lo que pienso voy a realizar, pachamama, ayudame. Dame pues valor, dame pues corazón grande. Yo te quiero pachamama», diciéndole hay que bendecirlo con alcohol ${ }^{60}$... iPhucha! bien puede ser singani, también puede ser singani «San Pedro».

«Bendecirlo con cariño, darle una ofrenda, con gusto, recien las pachamamas nos $d a^{61}{ }$. Hay que tener fe también así surgen todos los deseos que tienes. Todo va así para cualquier empresa, para minas, para cualquier cosa eso se hace. Para viaje también se hace. Los kallawayas siempre especialmente preparamos. Por ejemplo. . .

57 Saxta. Comida criolla a base de pollo cocido, ch `uño y tunta, variedades de patatas deshidratadas, como ingredientes característicos.

58 Thiтри. Plato criollo preparado con cordero, papas y ch'uñu, como ingredientes principales. PAREDES, A (1986), La comida popular boliviana, p. 318, La Paz. El thimpu de cordero y la saxta de pollo constituyen dos platos de prestigio entre los residentes urbanos paceños. Severino pretende resaltar el valor culinario de calidad que la ofrenda ritual supone.

59 La indiferenciación textual de género es muy frecuente en el contexto ceremonial andino y produce numerosas «incorrecciones» léxicas cuando se emplea el castellano. Santos, vírgenes, cerros y lugares sagrados comparten una ambigüedad de género que en ocasiones tiene un carácter lingüístico, pero en otros casos parece conceptual: vírgenes «señores» y santos «mamitas». Esta indiferenciación suele resultar más acusada en el caso de las imágenes importadas de España, sin embargo, «señor» pachamama, lo utiliza Severino para referirse a la madre tierra, en esta circunstancia, femenina. Hay que tener en cuenta la tendencia a elidir la última vocal en las lenguas andinas: «señor (a)».

$60 \mathrm{El}$ alcohol posee un valor sagrado relevante en el entorno cultural andino. SAIGNES, T (comp. ) (1993). Borrachera y memoria. La experiencia de lo sagrado en los Andes, La Paz.

Con él se efectúan las acostumbradas libaciones ceremoniales sobre las ofrendas. El símil de la misa católica en la realización de las mesas aymaras y kallawayas es frecuente aunque de contenido formal y sentido opuestos. FERNÁNDEZ, G. (1994), «El banquete aymara: Aspectos simbólicos de las mesas rituales aymaras», Revista Andina, 23, 155-189, p. 178, Cusco.

61 La mayor parte de los seres tutelares del altiplano y de las localidades andinas kallawaya establecen pactos de reciprocidad con los seres humanos a través de las atenciones ceremoniales y la ejecución de mesas rituales. FERNÁNDEZ, G. (1995a), El banquete aymara:Mesas y yatiris, La Paz. 
«yo soy Severino Vila, para mi viaje, para mi trabajo, para mi hogar, para mi salud». Así también tengo salud. . jbien! Así tiene que hacer las cosas. Así mis manos tienen que saber bien ${ }^{62}$. Por eso la gente también me busca. Yo no estoy así no más, siempre me llevan otro lugar, otro lugar. También me llevan hacia la frontera del Perú, también a los Yungas, a los trópicos, jen fin! todos los lugares camino. Hay que tener deseos. . . ¡no olvidar a la madre tierra! Es nuestra madre tierra. Para mesas en curaciones, especialmente en agosto, también puede ser en carnavales, también puede ser en espiritu, día de agosto, la tierra está abierta ${ }^{63}$. Entonces siempre alcanzan todos los que tienen empresas, fábricas, todos los diferentes vecinos se hacen un sahumerio para que no tenga problema, para que no tengan separaciones, para que no tengan ningún muerto. La tierra, cuando no le alcanzan hace atraso, no le pueden recuperar fracasos, si no es peleas, separaciones, si no es malignos parece, entonces lugar es mal. Entonces quien está mal hay que hacer pasar una mesita. Sullu de llama, dulce mesa, incienso, copal, pan de oro, untu de llama, huevo, feto, clavel, coca, alcohol. . . en sahumerio. «Pachamama, santa tierra, tierra virgen, disculpale, perdonale, yo te estoy alcanzando esta ofrenda. Este k'uchu ${ }^{64}$ recíbelo». Así, con este rezo hay que alcanzar a la tierra, santa tierra hay que hacerle pasar un brasito; con ese ya le perdonamos, no enfermamos, tampoco no hay problema. Cuando lugar está mal entonces otros se sienten afligidos, entonces una mesa será, al momento hay que preparar. Entonces cambio más siempre necesita. Necesario es eso. Cuando uno no tiene suerte, entonces nosotros cambiar también con animal, como puede ser con gallo, puede ser un conejo, cualquier animal, una limpiadita, con mesa negra ${ }^{65}$ diferentes clases de hierbas bañarlo, cintura abajo si no es su cuerpo, hay que bañar. . todas las desgracias, atrasos, maldiciones, hechizados que salga ipffiuuu! echarlo con agua».

«Agua hervidita también bañarlo a la persona, después limpiarlo todo y camino crucero botarlo. Eso se llama cambio de mala suerte. "Todas las desgracias, penas, rabias, atrasos, mala suerte que salga», diciendo hay que limpiarlo eso y entonces despacharlo camino crucero; eso es cambio de mala suerte».

$62 \mathrm{El}$ poder de las manos del curandero resulta muy importante. Parte de las rogativas ceremoniales aluden a esta circunstancia. RösING, I (1993), La mesa blanca callawaya. Variaciones locales y curación del susto, p. 63, Cochabamba/La Paz.

63 En agosto se inicia el ciclo ceremonial aymara, circunstancia compartida por los kallawaya urbanos de La Paz, coincidiendo con un alza apreciable en sus compromisos rituales con los clientes. La tierra se «abre», razón que justifica el sacrificio de ofrendas complejas durante todo el mes con especial atención a la víspera del primero de agosto. FERNÁNDEZ (1996b), p. 205.

${ }^{2} K^{\prime} u c h u$. El término k'uchu, «ángulo», alude a las esquinas, en concreto a los sacrificios ceremoniales que se colocan en los rincones de ciertas edificaciones. Así se denomina a los supuestos sacrificios humanos que soportan campanarios, puentes y otras edificaciones en el altiplano aymara.

65 Preparado ceremonial constituido por una diversidad de especies herbáceas queratinosas y sustancias orgánicas. Suelen emplearse en relación con la provocación del daño y su limpieza. 
«De los locos vamos a proceder también. Locos, muchas veces uno se vuelve ¿por qué vuelve loco? ¿Por qué vuelve loco? Loco puede ser. . . e es como decir trastornado, pero es trastornado. Ese loco, donde sea duerme. Una persona no es loco, pero estando sano, tiene problema tiene preocupaciones, tiene disgustos con sus concubinos. Por rabia me voy borracho o si no es a alguna parte se duerme, bosques, en los ríos, en las playas. Donde no anda gente duerme. Por eso, hay veces el demonio el anchancho se encontraron entre ellos ${ }^{66}$. Con espiritu, con anchancho o se lo ve la persona joh!, un toro se le aparece o un hombre aparece, un cóndor. Entonces la persona «iAy! cóndor» uno mira a otro lado, otro lado mira. . . . iya no hay ese cóndor! Entonces ese cóndor, le ha bajado totalmente su moral, ya no tiene ganas, no duerme, aflige. Quiere irse donde se ha asustado, a ese lugar no más, quiere irse a ese lugar no más; está pensando ir a ese lugar no más. Y si no tiene comida, cualquier rato qué cosa hace, qué otro hace; se puede desvertirse, se puede sacar sus calzones. . . ien fin! tantas cosas que pasan, o si no puede caminar pelado. ... «dejarme no más que tengo que ir». Los neurólogos, los psiquiatras no le hacen nada porque ihay que pagarlo! hay que darlo una ofrenda o sea esta mesita ;cambio! Podemos cambiar este señor con gato tres colores, una cataplasma hacia la espalda hay que colocarlo en la cabeza. Está en presión o temperatura interior tiene la cabeza. Por eso uno aflige, no hay voluntad quiere irse, como borracho está. Entonces cataplasma hay que poner, una mesa más hay que preparar como para la pachamama. . igualito. Una cataplasma con incienso, con copal molido, el gato hay que matarlo hay que hacer cargar el gato o si no es perro rojo o si no es gallo rojo o si no tres colores conejo. . . juno de los cuatro!. Ponemos cataplasma, podemos colocar eso y así. . . el persona por lo menos tiene que estar cargado unas tres horas. . o dos horas y media. Entonces jala todos sus malos sentidos que tiene, todo con su mesa, todo bien acostado en su cama. Bien amarrarlo tiene que chupar sus malos, chupa todo del cerebro que tiene mal, le jala; ya normalmente le acomoda. Entonces donde se ha asustado el joven, el hombre, el señor, hay que ir a enterrarlo al mismo lugar también, hay que hacer pasar, celebrar una mesita, "perdonale, disculpale, te lo estamos pagando. Suelta su animu, suelta su ajayu, suelta su espiritu» diciéndole hay que pagarlo «pachamama te lo estamos pagando esta ofrenda, suelta su animo, suelta su animo, suelta su animo, que venga su animo que no sea así tan nervioso, perdonale, disculpale», diciéndole hay que hacer pasar mesita y luego, ese gato que está en cataplasma rezando hay que bajarlo. Primer lugar es bajar rezando y luego igual también bajar rezando también el gato. Junto se va donde se ha dormido o donde se ha asustado».

66 Anchachu. Personaje maléfico que ocupa ciertas cárcavas y lugares poco transitados en las quebradas y rinconadas de los cerros. Posee una enorme facilidad para mudar su aspecto y aprovecharse de los incautos que se cruzan en su camino. 
«En ese lugar. . el persona que está enfermo tiene que dormir, no tiene que salir ningún lado, entonces nosotros rezándoselo llevamos la preparación, la cataplasma del gato donde se ha asustado, en ese sector, lo agujereamos, el gato enterramos, quemamos la mesita. Después de quemar, la ceniza, ahí mismo dejamos, en tierrita hay que alzar en forma de cruz, con su azucarcito hay que hacer llamar, hay que ir hasta su casa. Tiene que tomar también eso «perdonale, disculpale», jasí!».

«De la hierba fresca siempre vive en altiplano, en altiplano y hierba cálida en los yungas y hierba templada en medio valle ${ }^{67}$. Entonces en ese sector que vive la planta. Entonces diferentes lugares. En Caranavi, en Yungas es cálido, por ejemplo;

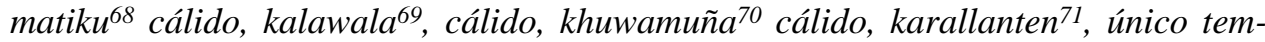
plado es eso. Siempre empleo con limón; con limoncito, con un poco de limoncito entra el matiku. Entonces, para esas cosas, especial mulli ${ }^{72}$, waji, cálido son. Copal ${ }^{73}$ también cálido, chachakuma ${ }^{74}$ ya altiplano es eso, hembra y macho. Hay que diferenciar, hay que mezclar. Uno cuando está siente digamos de riñón hay que mezclar. Mucho cálido, le hace mal al enfermo; tampoco no podemos puro fresco. No, no conviene. Mitad, mitad, entonces para que se suavice. Mediante eso ya preparamos. Ahora si es el persona, hay personas cálidas, hay personas frescas. Digamos persona cálida, Mentisán peor le hace, peor cálido prepara. Cosa fresca le hace bien. Hay persona que es frío entonces una cálida también le hace. No somos igual de gente. Gente fría es tranquilo, duerme; gente caliente es fatiga, uno no puede, busca mujer. . . temperamento es».

«Lindas cosas, las mejores alimentación, eso es más importante. Manzana verde, pata de ganado negro, su pata, oveja negra su pata, después frutas. . . jcualquier fruta!, arrocito, manzana verde, puede ser la uva, puede ser todo ¿no? en leche de vaca negra ${ }^{75}$. Hacer hervir, por lo menos cinco litros hasta que se cuece bien como una gelatina, todo deshace. Tomar como suero un vasito. Uno desmaya cuando está débil, hace dormir. Biensito se corrige».

67 El carácter «cálido» o «fresco» de las especies herbáceas y las diferentes sustancias empleadas en la farmacopea kallawaya no siempre dependen de la ubicación ecológica en que se encuentran. El polo sensorial seleccionado para la asignación de su «carácter» térmico no sólo depende de su localización física, el color, la forma de uso terapéutico. . . etc, inciden sobre la concreta clasificación térmica de la especie utilizada.

68 Matiku. (Piper sinoclausum ). GIRAUlt (1987), p. 149.

69 Kalawala (Polypodium Pycnocarpum). GIRAULT (1987), p. 103.

70 Khuwamuña (Satureja boliviana). GIRAULT (1987), p. 371.

71 Karallanten (Plantago hirtella). GIRAULT (1987), p. 410.

72 Mulli. (Schinus molle). GIRAULT (1987), p. 288.

73 Copal (Hymenaea sp). GiRAUlT (1987), p. 243.

74 Chachakuma (Escallonia micrantha). GIRAULT (1987), p. 215.

75 La incidencia del color en las sustancias empleadas en la terapia kallawaya es muy frecuente y alcanza especial expresión en relación con las ofrendas complejas. 
«Eso es caldo de cardán ${ }^{76}$, hígado de vaca, todo eso vitaminas hay que corregir; por ejemplo betarraga ${ }^{77}$, rábano ${ }^{78}$, esas cosas jvitaminazo son! Leche de vaca, walla$q e^{79} \sin$ aji ${ }^{80}$, pero se puede comino ${ }^{81}$, khuwamuña, nada más, porque no es necesario aji meter porque ataca al organismo. Entonces debe tomar, comer riquito».

«También podemos hablar de los sueños también se puede ${ }^{82}$. Cuando uno se sueña bajada, es atraso. Un sueño cuando subida subes es bueno. Sueñas recoges alguna cosa, paja. . . . jo que sea!, alguna piedra, cosa de fruta. . eso jes bueno! alegría. En sueños te caes, estás en agua sucia es para enfermar. Si ves ganados, muchos animales le ves ese es una preocupación. Agua limpia entras, ese es enfermarse, pero recuperas. Al espejo si ves un sueño en un espejo es traición, traición. Puede ser traición de mujer o traición de nuestros trabajos. Puede ser un trabajo que tenemos, otra persona recoge, ya no se puede realizar el trabajo, ese es el espejo. También sueño ves una vaca negra, toro, oveja eso es q `ullu $^{83}$; o jugadores que están jugando, deporte están saltoneando con pelota agarrado eso es mala señal, atraso. Cuando sueñas normalmente estás caminando o sueñas sale el sol es para larga vida porque tienes bastante salud».

«Lavaje» es para cosas vaginales. Se hace lavaje. Hay mujeres que tienen siempre dolores urinaria, dolor de ardores. Entonces hay que preparar manzanilla ${ }^{84}$, limón, mostaza ${ }^{85}$ y pipa de palta ${ }^{86}$, y si no hay pipa de palta, limón, ahora, si no hay limón, vinagre, dos cucharadas para un litro y medio. Tibia, limpio primero tiene que estar todo bien limpio. La jeringa, las tazas, bien limpio hacer hervir. Hacer hervir los mercurios. Hacer hervir biensito, limpio, cánulas todo. Taza le colocas esa latita, le echas todo bien cernido, tibia tiene que ser eso, al piel tiene que tocar. Ahí se echa, colocarlo cánula vaginal tamaño mediano. Colocamos todo ipfiuиu! todo de golpe, ese ardor ya no hay. Ovarios no más lava. Ahora si es limón, dos limonci-

\footnotetext{
76 Cardán: Pene.

77 Betarraga. Remolacha (Beta vulgaris). GIRAULT (1987), p. 179.

78 Rábano. Planta crucífera hortense de raíz carnosa.

79 Wallaqi. Plato típico del dominio altiplánico lacustre. Consiste en un caldo de pescado (qarachi) aromatizado con diferentes especies herbáceas del lugar, especialmente khuwamuña.

80 Ají (Capsicum annuum). GiRAult (1987), p. 394.

81 Comino (Cuminum cyminum). GIRAULT (1987), p. 339.

$82 \mathrm{El}$ campo de los sueños entre los indígenas americanos supone un ámbito de estudio importante desde la perspectiva antropológica. TEDLOCK, B (1995), «La cultura del sueño en las américas». En, KLOR De Alva, J et al (edit. ), De Palabra y Obra en el Nuevo Mundo. 4. Tramas de la identidad, p. $127-$ 169, Madrid. En relación con los Andes y su importancia entre los especialistas rituales aymaras, ver FERNÁNDEZ, G (1995b), «Imágenes, intelecto, palabras:El ojo del sueño en la formación de un «maestro» ceremonial aymara», Revista Andina, 26, p. 389-420, Cusco.

83 Q'ullu:Maligno. Se aplica a los huevos descompuestos, empleados en las prácticas de hechicería.

84 Manzanilla (Matricaria chamomilla). GiRAult (1987), p. 480.

85 Mostaza (Brassica nigra). GIRAULT (1987), p. 210.

86 Pipa de palta (Persea americana). GIRAUlT (1987), p. 202.
} 
tos hay que cortarlo hay que hacer hervir. Mostaza, manzanilla, limón, si no hay limón, vinagre, pipa de palta, la mitad».

«Ese limpia, tibia ipfffiuu! ese ya no tienen hijos. Cuando relación tienen algunos rapidito tienen wawa, le colocan agüita listo para eso. . ipffiuuu! ya no hay wawa, ya no hay wawa es que le mata el mercurio; todos los olores le saca rápido. Eso se llama lavaje».

«Para venéreas, hay pomadita. Debemos tomar una pomadita hay por ejemplo nosotros hacemos eso como chancroso es eso ¿no? Podemos preparar con grasa de llama, un poco azufre, un poco limón y de llamp`u de llama, ese es. Como vinagre aquí tocan, punzan, sale. Primero hay que lavar limpio con Andres waylla ${ }^{87}$. Hay que lavar todo bien. Después colocarlo con mentisán. Esto sus microbios lo mata, mata todo jaggg! doliendo siempre ¿no? Después seguir lavando con Andres waylla aunque se fresco lavando, lavando, poco a poco, así. Ahora, si no sana. . . jen pinchazo no más! pero es peligroso».

«Los kallawayas tienen que manejar su crucifijo, debe manejar su navaja, debe manejar su campanita. El cuchillo es defensa del kallawaya. Defensa del kallawaya es su crucifijo. El kallawaya duerme tranquilo. No le molesta nadie. Una señal hablando con demonio, el demonio se acerca. . . . «iNo! tiene crucifijo. . . es de dios!», por sí se aleja;se hace a un lado» ${ }^{88}$.

«Ahora las personas que no saben. Hay secretos de los kallawayas muy distintos. Así nosotros siempre viajamos lejos. Puro creo que todos lugares viajamos; campos donde no hay gente, raras casas, parte por parte hay casas, visitamos con medicamentos. En noche siempre nos asusta un perro o una persona o animal en camino. Nosotros tenemos sabiduría, no necesitamos esas cositas, pero nosotros tenemos secreto oculto. El kallawaya hace cuando uno asusta su secreto sale. Tres veces he escupido ¡taj, taj, taj! La tierrita así en forma de cruz alzo. . . ya itranquilo! no hay nada sano el persona. Si me duele cabeza, un jaloncito ;Taj! ya está ;sano! Ese es secreto del kallawaya. Hay otros que se orinan o su baño hacen. Eso es un k`intu ${ }^{89}$, dejar eso.

87 Andres waylla (Cestrum hediondinum). GIRAULT (1987), p. 388.

${ }^{88}$ El crucifijo es adoptado como emblema de poder, a inspiración de los objetos rituales del sacerdote, por diferentes especialistas rituales, especialmente en el dominio rural paceño. Estos crucifijos presentan una decoración peculiar a base de cuentas de colores con superposición de imágenes que reflejan la competencia ceremonial del «maestro» que lo porta. En realidad semejan grandes «rosarios» que algunos maestros ceremoniales utilizan acompañando a los ensalmos e imposiciones que realizan durante los procedimientos rituales. El crucifijo como símbolo de poder sagrado es portado igualmente como emblema de autoridad por parte de los cargos consuetudinarios más importantes en ciertos sectores del altiplano aymara. Así lo portan los mallkus de Machaqa (provincia Ingavi Departamento de La Paz), entre otros.

89 K'intu. Ofrenda de hojas de coca consistente en tres o cinco hojas de especial calidad que se depositan sobre los lugares sagrados. Las defecaciones son escondidas con preocupación por las derivaciones que su empleo puedan tener en propiciar hechizos malignos por parte de los layqas (brujos). 
Depende ponerse fuerte, animoso, corajudo, astuto hay que ser. . ;no tener miedo!. Ese es secreto del kallawaya».

\section{MEdicina y CUltura Kallawaya}

Las informaciones de Severino nos sitúan frente a una conceptualización de la enfermedad sustancialmente diferente de los cánones transculturales que la medicina convencional académica pretende. La incidencia de prácticas y teorías médicas de diferente procedencia y adscripción define la concreción múltiple y dispar que sustenta la figura de los kallawayas urbanos de la ciudad de La Paz. El conocimiento de especies herbáceas y otras sustancias relacionadas con la farmacopea tradicional y su empleo terapéutico se combina sin fricción alguna con diferentes hipótesis sobre la naturaleza y etiología de las enfermedades, una de ellas de probable inspiración hipocrática, para complementar y aplicar de forma especializada una medicina ritual que, en lo que se refiere a los fundamentos de reciprocidad que contiene el proceso de sanación a cambio de ofrendas complejas, coincide con la valoración indígena efectuada sobre la naturaleza y tratamiento de la enfermedad en otras sociedades andinas, algunas próximas a la esfera añeja de intervención terapéutica kallawaya ${ }^{90}$.

Ciertas denominaciones castellanas de enfermedades como «mareo», «hemorragia», «anemia» y «locura» están referidas a síndromes difícilmente reconocibles, si no es dentro de las pautas características de la etiología kallawaya. Llama la atención la importancia otorgada a la conceptualización de la persona, benefactor último de las prácticas desempeñadas por los kallawayas en el tratamiento de la enfermedad. La configuración de la persona adquiere una relevancia apreciable en el entorno $\mathrm{ka}$ llawaya, circunstancia que comparte con otros grupos andinos, y que no resulta en absoluto ajena a la caracterización nativa de la enfermedad y, por tanto, a la pertinencia de los procedimientos terapéuticos empleados. No sólo la enfermedad, su etiología y tratamiento aparecen perfilados en la trama que teje la cultura en cada caso, sino que la propia categoría de «persona» contempla igualmente en su anatomía explícita, características peculiares definidas en su seno. Los modelos de proyección anatómica inspirados en la figura del «cuerpo montaña» y la transmisión de fluidos, así como el hermetismo de la piedra aparecen recogidos en diferentes monografías sobre los kallawayas y otros grupos andinos próximos, justificando formas diversas

90 CONTRERAS, J. (1985), Subsistencia, ritual y poder en los Andes, Barcelona. FERNÁNDEZ, G. (1995c), «Modelos aymaras de salud:Ajllata Grande (Provincia Omasuyos)», Anales de la Reunión Anual de Etnología (1995), 76-103, La Paz. GuERRA, A. (1991), Chipaya. Un enigmático grupo humano, ORURo De LA ZERDA, J. (1993), Los chipaya:modeladores del espacio, La Paz. ALBA, J.J. et al (1993), Los jampiris de Rakaypamapa, Cochabamba. 
de atención médica y terapéutica ${ }^{91}$. Este aspecto nos llevaría incluso a establecer lazos de referencia entre ciertas sociedades andinas y las piedras, cerros y montañas que las rodean con las que comparten un cuerpo social biológicamente activo, consolidado en los mútiples actos rituales que se efectúan en los perfiles sagrados de su espacio anatómico, así como un carácter diferenciado socialmente, en función del propio talante de las piedras ceremoniales (huacas y «calvarios») que acogen de forma emblemática la tutela de cada población ${ }^{92}$.

Por otra parte, la ligazón estrecha existente entre cuerpo y alma no como dos realidades excindidas si no formando parte del mismo tejido celular, plantea nuevas opciones y posibilidades a los modelos de formulación terapéutica indígenas.

La variedad de entidades anímicas que conforman el alma de la persona en diferentes sociedades andinas, caso del «ajayu», el «animu», el «espiritu» o el «coraje», establece una relación unívoca entre el cuerpo y todas sus almas de cuya correcta urdimbre depende la salud y vitalidad de los humanos ${ }^{93}$. Si consideramos que los kallawayas y otros grupos indígenas hablan de personas «diferentes» a las enmarcadas en la tradición médica occidental, resulta razonable considerar que existan otras terapias apropiadas para la resolución de los síndromes y patologías encuadrados en las pautas culturales de cada uno de los grupos implicados.

91 BASTIEn, J. (1996), La montaña del Cóndor. Metáfora y ritual en un ayllu andino, p. 73-86, La Paz. Fernández (1995a), p. 280.

92 Rösing, I. (1996a) Rituales para llamar la lluvia, La Paz-Cochabamba. BASTIEN, J. (1986) «Etnofisiología andina. Evidencia Lingüística, metafórica, etiológica y etnofarmacológica para conceptos Andinos sobre el cuerpo». Arinsana, 1, 5-24, Cuzco. BERNAND, C.M. (1986) Enfermedad, daño e ideología, Quito.

${ }^{93}$ La etnografía andina no aporta grandes cosas en relación con los perfiles iconográficos de la pluralidad de entidades anímicas que integran el alma humana o por lo que respecta a esta variedad de «almas» que constituyen la persona. No ocurre así entre los indígenas mesoamericanos, particularmente los de origen maya, cuyo interés por el alma y los acontecimientos que suceden a las diferentes almas de la persona ha sido recogido en diversos estudios y monografías que acuciosamente describen, incluso en términos iconográficos, el perfil de dichas entidades. PITARCH, P. (1996), «Animismo, colonialismo y la memoria histórica tzeltal», Revista Española de Antropología Americana, 26, p. 183-203, Madrid. Respecto a las sociedades andinas encontramos escasas alusiones. Algunas referencias de Polia (POLIA, M. 1989)» «Contagio» y «pérdida de la sombra» en la teoría y práctica del curanderismo andino del Perú Septentrional:Provincias de Ayabaca y Huancabamba». Revista Anthropológica del Departamento de Ciencias Sociales, 195-231, p. 197, Lima), en el Norte peruano sobre la «sombra», aspecto ya recogido por el antiguo vocabulario de Bertonio (BERTONIO, L. (1612/1984), Vocabulario de la lengua aymara, $\mathrm{p}$ 108, Cochabamba ). Berg (BERG, H. (1985), Diccionario religioso aymara, p. 13, Iquitos) y Carter y Mamani (CARTER, W. y MAMANI, M. (1982), Irpa Chico. Individuo y comunidad en la cultura aymara, p. 348, La Paz), realizan algunas disquisiciones sobre los ajayu aymaras , pero de carácter muy general. A pesar de las informaciones constantes sobre la creencia de la pérdida del alma como enfermedad en cualquier monografía de estudios andinos, poco conocemos sobre esas almas que se «pierden». 
Los acontecimientos del alma, de cada una de estas parcelas anímicas que poseen cierta autonomía existencial, pero ligadas a la «disciplina de grupo», implican consecuencias directas sobre el cuerpo, sobre la masa orgánica que las integra.

Cada una de las modalidades constitutivas de la diversidad que caracteriza al alma de los seres humanos es susceptible de ser «agarrada», apresada por un conjunto de seres tutelares que forman parte de la ecología altiplánica y valluna donde se inserta la vida kallawaya. Los cerros, la tierra, los rayos, las ruinas y tumbas antiguas así como los temibles anchanchus y ñanqhas que habitan las cárcavas y lugares solitarios, configuran un cuadro variopinto de entidades dispuestas a establecer una relación de reciprocidad con los seres humanos, donde la salud es motivo de negociación ritual en torno a la etiqueta de un banquete complejo. El ajayu, una de las parcelas constitutivas del alma de los seres humanos, es su sombra y constituye un «doble» exacto de la persona.

En aymara se denomina a las sombras que integran el alma de las personas kimsa ch'iwi, las tres sombras gemelas ${ }^{94}$. Un viejito aymara de la comunidad de Qorpa, Jesús de Machaqa, provincia Ingavi del departamento de La Paz, me confió que el ajayu es nuestra propia sombra, constituida en forma apreciable por el conjunto de las diferentes entidades a las que me he referido con anterioridad. El ajayu, el espiritu y el coraje muestran diferentes tonalidades que pueden apreciarse en los destellos de la sombra. La pérdida de una u otra sombra implica una mayor o menor gravedad en la dolencia proporcionada sobre el cuerpo y, en este sentido, una exigencia y premura mayor en su rescate por parte del kallawaya. Esos personajes que pueblan los valles interandinos y el altiplano capturan cualquiera de las almas que las personas poseen con la intención frecuente de recriminar ciertos comportamientos improcedentes en el ajustado engranaje que sostiene la relación entre los seres humanos y sus celosos progenitores ceremoniales.

La conceptualización de la persona afecta, igualmente, a su talante y carácter térmico de indudable inspiración hipocrática, concepto introducido con la conquista española ${ }^{95}$. Existen personas «cálidas»y personas «frescas», como nos indica Seve-

\footnotetext{
94 Durante mi última temporada de campo en Bolivia, los meses de Octubre a Diciembre de 1996, he recogido en dos comunidades aymaras altiplánicas distintas y apartadas entre sí, una información pareja sobre la naturaleza de las almas que forman parte de la persona en el altiplano. El alma está constituido por tres sombras gemelas (kimsa ch'iwi) que configuran una sombra con triple contorno cromático diferenciado (de adentro hacia afuera negro, semioscuro y claro) que hacen apreciable los diferentes dobles de la persona, correspondientes a su «ajayu», «animo» y «coraje». Su inspiración responde al modelo de la Trinidad católica que hace al ajayu, alma principal, entroncarse con la naturaleza del Padre, al animu, alma secundaria, con la naturaleza del Hijo y al coraje, alma terciaria, con la del Espiritu Santo.

95 Kuschick, I. (1995) Medicina popular en España, 80-83, Madrid. Bien es cierto que otros autores en relación con la cultura kallawaya como Joseph Bastien, defienden un origen precolombino para este tipo de categorías. Considera que el concepto estaba, al menos parcialmente, presente en los Andes antes de la llegada de los españoles (BASTIEN, J (1986), p. 18-22).
} 
rino, para las cuales resulta imprescindible considerar el tratamiento más adecuado ${ }^{96}$. El equilibrio térmico, respecto a las cualidades reflejadas por el especialista, basado en la armonía de los contrastes exige, para un mismo tipo de dolencia, prácticas terapéuticas diferenciadas en función del talante inquieto (cálido) o reposado (frío) del paciente. Las personas somos diferentes y reaccionamos de forma orgánica contrastada en función de nuestro propio carácter distintivo. No existe una terapia unívoca que se pueda aplicar de forma universal a determinado tipo de dolencia sobre los cuerpos enfermos de los pacientes. Esta analítica térmica obliga a una atención casi individualizada del paciente, considerando el tratamiento que mejor se ajusta a las características peculiares del mismo.

A pesar de los rasgos sintomáticos genéricos que podemos encontrar en la medicina practicada por los kallawayas y que les permite identificar determinados síndromes y sus pertinentes terapias, esta circunstancia supone un serio enfrentamiento respecto a las potencialidades universalizadoras de corte transcultural que la medicina académica propugna.

La atención individualizada que mejor se ajusta a la casuística propia del enfermo es uno de los perfiles propios de la medicina kallawaya paceña; reconoce enfermedades, pacientes y tratamientos diferenciados que se ajustan mejor de forma diferenciada a las peculiaridades específicas del enfermo. Por esta circunstancia se puede modificar un tratamiento de carácter «cálido», por otro «fresco» si mejor refleja la afinidad curativa del paciente. Las peculiaridades del equilibrio térmico que el maestro kallawaya pretende conciliar, utilizando toda suerte de especies herbáceas para infusiones y emplastos, se basa en idéntico concepto. No es bueno abusar ni de especies cálidas, ni de especies frescas, no hay que potenciar el extremo, sino el término medio.

El miedo, la dejadez manifiesta en el cumplimiento de las obligaciones diarias, la pereza y una voluntad voluble constituyen claros síntomas de enfermedad, desde la perspectiva kallawaya. De hecho, los tímidos y apocopados son personas a las que se achaca un estado enfermizo endémico. Sólo los «corajudos», los que no temen, se dice que difícilmente son «vencidos» por la enfermedad.

El código visual, sensible posee una importancia resaltable en el ejercicio de la medicina kallawaya, particularmente en su componente ritual. Por un lado, las ofrendas complejas adquieren una dimensión cromática espectacular donde todos los sentidos son hábilmente excitados por el hacer del especialista. Por otra parte, la selección de ciertas especies animales empleadas en las curaciones kallawayas se deben a los peculiares matices de color que presentan.

96 Los aymaras diferencian igualmente entre el carácter cálido o frío de las personas, insistiendo, según Vokral (VoKRAL, E. (1991), Qoñi-chiri. La organización de la cocina y estructuras simbólicas en el Altiplano del Perú, p. 285, Quito), en una estricta diferenciación de género. La mujer es considerada «cálida» en relación al número de hijos que tiene. Las mujeres infértiles son consideradas frías, como los varones. 
Junto a la conceptualización de la persona por parte de los kallawayas bolivianos llama la atención la etiología otorgada a diferente tipo de dolencias relacionadas con el entorno ecológico donde la gente realiza sus actividades cotidianas. El rayo, el arcoiris, la madre tierra, los cerros. . . . etc, son agentes patógenos que pueden causar diferentes enfermedades, precisamente aquellas que tienen especiales implicaciones y efectos sobre las almas de las personas. Los lugares físicos que no están atendidos convenientemente, en relación a sus necesidades alimenticias, enferman y se encuentran, igualmente, en disposición de hacer enfermar a los inquilinos; son malos lugares, lugares insanos, culturalmente insalobres. Se aplica al espacio físico idéntica cualidad que al paciente enfermo. En este sentido es preciso atender a esa diferenciada pléyade de personajes que pueblan el espacio kallawaya con las correspondientes comidas que mejor se ajustan a sus gustos culinarios: las mesas rituales. La comida, el banquete ritual constituye una de las formas apreciables de mayor reconocimiento, prestigio y eficacia en el que la enfermedad del paciente puede «negociarse» con los causantes de la misma que son agasajados a través de la ofrenda.

El cambio «salud por comida ceremonial» resulta pertinente en el planteamiento etiológico de la enfermedad que impera entre los kallawayas y otros grupos afines ${ }^{97}$. Por otra parte, la práctica ritual de las ofrendas complejas constituye un atractivo modelo de medicina preventiva cuya razón de ser se fundamenta en la cordialidad y mutuo compromiso de relación que se establece entre oficiante, oferente y destinatario sagrado.

La mesa supone una estrategia terapéutica proyectiva. El maestro manipula los ingredientes de la ofrenda reproduciendo el entorno simbólico de Charazani, haciendo participar a los diferentes lugares sagrados del ámbito kallawaya y del altiplano en la resolución del conflicto que provoca la aflicción del doliente ${ }^{98}$. La escenificación simbólica de los lugares de «poder» propios de los maestros kallawayas intervienen, a través de su convocatoria en el banquete de la ofrenda, para la resolución del conflicto. Los maestros kallawayas reproducen y otorgan una significación concreta al entorno kallawaya recreando esa anatomía simbólica local al incluir cada especie ceremonial en la ofrenda. El valor repetitivo de esta configuración ceremonial referida a los cerros, calvarios y chullperíos propios del sector, que son convoca-

97 Rösıng, I. (1995a), La mesa blanca callawaya. Contribución al análisis. Observaciones intraculturales y transculturales, p. 78, La Paz-Cochabamba.

98 En el dominio aymara se produce una significación pareja. El espacio sagrado es reproducido permanentemente al nombrarlo el yatiri cada vez que incluye uno de los ingredientes ceremoniales en la ofrenda. Por otra parte la mesa adquiere un marcado sentido anatómico al reproducir un cuerpo perfecto, el cuerpo del doliente elaborado con el conjunto de ingredientes de la mesa al ubicarlos el yatiri en el lugar que les corresponde, al tiempo que los diferentes lugares sagrados del sector son nombrados según un pulcro orden de autoridad y una orientación específica (FERNÁNDEZ (1995a), p. 253-349). El cuerpo físico del enfermo es configurado de nuevas con los ingredientes del maestro, las plegarias y el nombramiento del espacio anatómico ceremonial comunitario, resultante del propio convite ritual. 
dos a medida que el kallawaya los nombra e incluye en la ofrenda, incrementan el poder del plato ritual y constituye un paradigma ejemplar de convocatoria colectiva, al convidar, en el orden estipulado, a todos los lugares de poder que tienen competencia en el caso y que debatirán, como acostumbran hacerlo los seres humanos, en asamblea en torno a los manjares y bebidas predilectas que mejor se ajustan a sus preferencias. En relación con las ofrendas complejas kallawayas existe una figura, el ankari, el viento, que realiza labores de intermediación respecto a los destinatarios sagrados y que se encuentra representado en el huevo de la ofrenda ${ }^{99}$.

La mala suerte, el fracaso tenaz e incluso la locura, son signos de enfermedad que pueden modificarse con el pertinente cambio. Un animal desollado de especiales cualidades cromáticas, (gallo rojo, perro negro, conejo de tres colores), es desollado y colocado sobre el paciente durante un tiempo para luego sacrificarlo en el lugar donde se produjeron los hechos desencadenantes de «mala suerte», junto a una ofrenda ritual. El animal representa al enfermo, lleva impregnado en su cuerpo abierto la dolencia del paciente.

El animal se entierra en el cementerio donde se alojan los difuntos humanos; con él se inhuma la mala suerte del doliente y la condición patógena del enfermo quien surge sano de la experiencia ${ }^{100}$.

Rayos, cerros, arco iris, ofrendas, plantas y almas integran un variopinto cuadro escénico en el que el conocimiento de los kallawayas se implica en el modelo de reinterpretación del mundo que conlleva el proceso de sanación. La recuperación de las almas capturadas por alguno de los agentes tutelares del medio ecológico, la infracción de las normas consuetudinarias que derivan en procesos de enfermedad colectiva (por ejemplo el ejercicio de los ritos colectivos de perdón tras catástrofes naturales como la sequía), el cuidado ceremonial periódico del entorno ecológico ${ }^{101}$, la reflexión permanente sobre la naturaleza de la persona y su variada composición

99 RösING, I. (1990a), «El Ankari. Figura central y enigmática de los Callawayas (Andes bolivianos)», Anthropos-Revista Internacional de Etnología y Lingüística, 85;73-89, Sankt Augustin. MARZAL, M. (1971) «¿Puede un campesino cristiano ofrecer un «pago a la Tierra»?» Allpanchis Phuturinqa, Vol. 3; 116-128, Cusco.

100 En el entorno aymara paceño esta práctica recibe la peculiar denominación de «muerte cambio». El animal desollado, una vez que se ha colocado por espacio de varias horas sobre el cuerpo del paciente, en su espalda, la nuca, la cintura o los pies, dependiendo de la sintomatología que la dolencia presente, se entierra en el cementerio con el nombre del enfermo, realizando varias libaciones alcohólicas en nombre del paciente sobre el cuerpo del animal y el resto de abalorios rituales que lo acompañan . De esta forma el doliente «muere» bajo la apariencia del animal desollado que se ha empleado en su tratamiento al ser enterrado en lugar del enfermo, con su nombre, llevándose a las sombras la enfermedad.

101 IsBell B.J. (1978) To Defend Ourselves: Ecology and Ritual in an Andine Village. Latin American Monographs, $N^{\circ} 47$, Austin. OssIO, J. (1978), «El simbolismo del agua y la representación del tiempo y el espacio en la fiesta de la acequia de la comunidad de Andamarca», Actes du XLII Congrès International des Américanistes 4, p. 377-395, París. VALDERRAMA C. y ESCALANTE R. (1988), Del tata mallku a la mama pacha. Riego, sociedad y ritos en los Andes peruanos, Lima. 
anímica y biológica, el tratamiento de las especies herbáceas, la implicación del entorno familiar en los diferentes sistemas de atención terapéutica y la salvaguarda del hermetismo orgánico de los cuerpos, muestran una perspectiva integral de la enfermedad sustancialmente distinta de los modelos biologicistas propios de la medicina académica. En este sentido, las prácticas médicas kallawayas guardan una afinidad importante respecto a las conceptualizaciones etiológicas y terapéuticas de otros grupos étnicos del Sur andino.

La relación de los médicos kallawayas con los equipos formales de salud, especialmente a través de la institución SOBOMETRA va concitando diferentes convenios y campos de actuación multidisciplinar, lo que permite a los pacientes, al menos en La Paz, rotar por las diferentes opciones que el mercado de la salud ofrece, en la medida en que su economía lo permita. En este espectro diferenciado es posible encontrar posturas enfrentadas entre curanderos, médicos y pacientes, así como otras de carácter complementario.

\section{CONCLUSIÓN: UNA PERSPECTIVA INTERCULTURAL}

El ejercicio médico convencional en países de marcado carácter pluricultural, como es el caso de Bolivia, supone un esfuerzo constante de negociación intercultural. Las altas tasas de mortalidad infantil entre el primer y el quinto año de edad (según datos recientes de la OMS se aproximan al 250/1000), obligan a tomar indudablemente en serio las directrices y orientaciones que las políticas sanitarias internacionales demandan del Estado boliviano.

La delegación de esta responsabilidad en Organizaciones No Gubernamentales de Desarrollo (ONGs) internacionales y la formación universitaria de licenciados en medicina y profesionales sanitarios sin ningún área formativa o simplemente informativa en su perfil curricular académico, sobre la diversidad cultural y las peculiaridades del entorno social donde van a ejercer su profesión, acrecienta una zanja crítica de separación entre las formas de la medicina étnica y las manifestaciones habitualmente prepotentes de los equipos sanitarios convencionales. Por otro lado, las relaciones de poder que se establecen entre los equipos médicos y sus pacientes indígenas, dificultan la resolución favorable de los conflictos que se producen al tratar sobre las medidas terapéuticas a seguir.

La autoridad y competencia médicas, las formas de terapia, la relación entre médico y paciente, la implicación familiar y social de la enfermedad, el gravamen económico, el sentido de eficacia de las prácticas terapéuticas, constituyen aspectos claves que resultan sustancialmente diferentes entre los modos y formas que presentan en los equipos convencionales y los que adoptan en el seno de las diferentes culturas indígenas americanas. 
El ejemplo de la medicina kallawaya, su forma peculiar de concebir la salud, la enfermedad y las medidas terapéuticas pertinentes en ese triple registro configurado por concepciones de origen popular hispánico, elaboraciones rituales relacionadas con una tecnología y eficacia simbólica que aparecen reflejadas de forma temprana en las crónicas coloniales andinas y un extenso conocimiento de farmacopea popular, reflejan el sentido de una medicina inserta en las claves culturales soportadas por los médicos kallawayas y relacionadas con su propio medio habitual de existencia.

Los prejuicios y las displicencias habituales en quienes ejercen la acción médica convencional respecto a las medicinas étnicas, nada tienen que ver en el análisis objetivo de una disciplina como la medicina que se muestra próxima a las ciencias humanas y sociales puesto que son seres humanos, implicados en densas redes de comportamiento social, su herramienta habitual de trabajo y análisis. La medicina constituye un eslabón de importancia en la trama que sobre las sociedades humanas tejen sus respectivas culturas. El profundo sentimiento humanista que aparece inmerso en las prácticas médicas kallawayas, su dedicación y lógicas explicativas, su acuciosa observación en el conocimiento de ciertos principios farmacológicos aislados en las especies herbáceas de su entorno, debieran hacernos reflexionar sobre la humanización de la medicina occidental; sobre nuestros pacientes igualmente sometidos a construcciones culturales complejas relativas a las enfermedades y sus propuestas curativas, en relación con las posibilidades de una mejor satisfacción de servicios sanitarios en nuestras propias instituciones hospitalarias, identificando las necesidades y carencias contrastadas por los usuarios.

Las medicinas étnicas, como es el caso de la medicina practicada por los indígenas kallawaya, no pueden dejarse en manos de desaprensivos y exotistas iluminados que sostienen principios de carácter transcultural en aplicaciones médicas que responden a demandas concretas surgidas en contextos culturales precisos, bien delimitados y que responden a necesidades y construcciones culturales propias donde resultan eficaces. Otra cosa significa el estudio de los principios farmacológicos contenidos en las especies naturales empleadas y sus dosis pertinentes. Por otra parte, desde la antropología resulta gratificante contrastar la diversidad de opciones planteadas por los diferentes grupos étnicos americanos en relación con el tratamiento de la enfermedad. Gratificante en el sentido de resistencia y freno a las pretensiones de globalización cultural que imperan en estos tiempos, pero preocupante, por otra, debido a la política y el ejercicio de la autoridad efectuada por las diversas herramientas de los Estados pluriculturales latinoamericanos y sus flecos desarrollistas más o menos implicados en los planteamientos gubernamentales desde ciertas subsecretarías como la existente en Bolivia ( «género, etnias y generaciones») hasta las propias Organizaciones No Gubernamentales (ONG) de desarrollo, cuando tienen que hacer frente a situaciones críticas de salud en los contextos habituales de marginación como los que soportan los grupos indígenas contemporáneos. 
Las penosas estadísticas referidas al parámetro de mortalidad infantil en buena parte de las zonas ocupadas por los grupos indígenas, plantea serios problemas éticos en el ejercicio de la antropología y la medicina convencional. La dificultad por crear espacios de diálogo intercultural extrema la distancia y los enfrentamientos entre los curanderos tradicionales indígenas y los servicios formales de salud. Las peculiaridades culturales no son consideradas o lo son de una forma displicente por los equipos sanitarios formales forzados a cumplir con ciertos registros estadísticos para asegurar su propio presupuesto.

Así las cosas, la importancia del conocimiento de la lengua indígena y de las conceptualizaciones nativas en torno a la enfermedad, por parte de los equipos de salud que trabajen en los espacios rurales, nunca será suficientemente remarcada. Su implicación paulatina, sin violencia, en la esfera social; el acomodo en las actividades habituales de las comunidades indias posibilitará un espacio de diálogo donde la medicina y la enfermedad sea objeto de reflexión desde perspectivas dispares. La multiculturalidad obliga a la búsqueda de soluciones igualmente múltiples y diferenciadas en el tratamiento de las enfermedades; a su consideración desde perspectivas distintas a las directrices unívocas que emanan del aparato administrativo del Estado. El contacto con los representantes nativos de la medicina tradicional, nunca en contextos de competitividad sino de colaboración, y la formación de una red de apoyo de auxiliares sanitarios nativos locales, pueden ayudar a cimentar situaciones de afinidad y confianza entre pacientes y equipo sanitario, indispensables para el ejercicio de la labor médica en situaciones de marcado contraste cultural.

En Bolivia, la obligatoriedad que tienen los egresados de la Facultad de Medicina de cubrir un «año de provincias» para obtener el título en provisión nacional, supone un grave contratiempo para cualquier intento de integración o diálogo intercultural. Aquellos egresados que se lo pueden permitir pagan un dinero para no tener que realizar el «año de provincias», acontecimiento que no pocos sienten como exilio forzado entre la «indiada», en el sentido más despreciativo del término. En esta situación es difícil que se creen redes de afinidad con la población asistencial local. Surgen los roces y tensiones habituales que dificultan, en grado extremo, la integración de la posta y su reconocimiento en la comunidad indígena, supuestamente «beneficiaria» de su presencia.

Por otro lado, los pacientes indígenas quieren calidad y continuidad; es decir, tienen la convicción de que los médicos rurales son «principiantes», «inexpertos» que vienen precisamente a aprender practicando con ellos. Por otra parte, cuando alguno de estos equipos médicos se integra en la población de acogida, no es mucho lo que pueden hacer, puesto que el relevo se produce con prontitud al año de su ejercicio. Esta circunstancia dificulta en gran medida las posibilidades de integración de las postas, puesto que depende del talante de los sucesivos equipos médicos que se incorporan en el puesto. 
Para concluir quiero retomar las últimas manifestaciones de Severino en su testimonio kallawaya. Le preguntaba precisamente por la relación entre médicos y kallawayas en la ciudad de La Paz.

«No está bien. De todos modos hay relación. Hay relación. Ya ha reconocido el gobierno todo ${ }^{102}$. Casi. . el mismo camino; como decir científicos, dicen. Los doctores. . igual, muchas veces también curan. . . , pero muchas veces tampoco no curan; eso es lo uno por lo otro. Ahora el médico, cuando no puede. . el curandero cura; el curandero no puede. . el médico cura. Lo uno por lo otro. No es, tampoco no puedo decir que el médico no cura. Cura también, cada uno su persona; cada maestro tiene su técnica de curar, diferentes clases. Entonces igual también, los médicos también. Los médicos también, algunos no pueden. . . entonces, el curandero. . . ile cura!. Ese sería».

Las palabras de Severino muestran el talante de una disciplina científica como la medicina que no acostumbra a comportarse como una ciencia exacta (no cura en todas las ocasiones), y cuyas posibilidades de ejercicio en La Paz se basan en las leyes de mercado y en la variedad que las diferentes opciones terapéuticas ofrecen a los enfermos, en función de los distintos representantes de la medicina, ya sea convencional o indígena. En unas circunstancias cabe la complementación terapéutica, en otras predomina la exclusividad. Este talante intercultural que muestra Severino resulta hoy por hoy impensable en la clase médica boliviana, respecto a su «colegas» curanderos. El ejercicio intercultural en relación con las demandas bolivianas en la esfera de la salud ha de ser simétrico para resultar efectivo.

102 Se refiere a las resoluciones presidenciales que han confirmado el reconocimiento institucional de SOBOMETRA. 